\title{
Nitrogen and sulfur deposition on regional and global scales: A multimodel evaluation
}

\author{
F. Dentener, ${ }^{1}$ J. Drevet, ${ }^{2}$ J. F. Lamarque, ${ }^{3}$ I. Bey, ${ }^{2}$ B. Eickhout, ${ }^{4}$ A. M. Fiore, ${ }^{5}$ \\ D. Hauglustaine, ${ }^{6}$ L. W. Horowitz,${ }^{5}$ M. Krol, ${ }^{1,7,8}$ U. C. Kulshrestha, ${ }^{9}$ M. Lawrence, ${ }^{10}$ \\ C. Galy-Lacaux, ${ }^{11}$ S. Rast, ${ }^{12}$ D. Shindell, ${ }^{13}$ D. Stevenson, ${ }^{14}$ T. Van Noije, ${ }^{15}$ \\ C. Atherton, ${ }^{16}$ N. Bell, ${ }^{13}$ D. Bergman, ${ }^{16}$ T. Butler,${ }^{10}$ J. Cofala, ${ }^{17}$ B. Collins,${ }^{18}$ \\ R. Doherty ${ }^{14}$ K. Ellingsen, ${ }^{19}$ J. Galloway, ${ }^{20}$ M. Gauss, ${ }^{19}$ V. Montanaro, ${ }^{21}$ J. F. Müller, ${ }^{22}$ \\ G. Pitari, ${ }^{21}$ J. Rodriguez, ${ }^{23}$ M. Sanderson, ${ }^{18}$ F. Solmon, ${ }^{11}$ S. Strahan, ${ }^{23}$ M. Schultz, ${ }^{12,24}$ \\ K. Sudo, ${ }^{25}$ S. Szopa, ${ }^{6}$ and O. Wild ${ }^{25,26}$
}

Received 13 December 2005; revised 7 April 2006; accepted 8 May 2006; published 28 October 2006.

[1] We use 23 atmospheric chemistry transport models to calculate current and future (2030) deposition of reactive nitrogen $\left(\mathrm{NO}_{\mathrm{y}}, \mathrm{NH}_{\mathrm{x}}\right)$ and sulfate $\left(\mathrm{SO}_{\mathrm{x}}\right)$ to land and ocean surfaces. The models are driven by three emission scenarios: (1) current air quality legislation (CLE); (2) an optimistic case of the maximum emissions reductions currently technologically feasible (MFR); and (3) the contrasting pessimistic IPCC SRES A2 scenario. An extensive evaluation of the present-day deposition using nearly all information on wet deposition available worldwide shows a good agreement with observations in Europe and North America, where $60-70 \%$ of the model-calculated wet deposition rates agree to within $\pm 50 \%$ with quality-controlled measurements. Models systematically overestimate $\mathrm{NH}_{\mathrm{x}}$ deposition in South Asia, and underestimate $\mathrm{NO}_{\mathrm{y}}$ deposition in East Asia. We show that there are substantial differences among models for the removal mechanisms of $\mathrm{NO}_{\mathrm{y}}, \mathrm{NH}_{\mathrm{x}}$, and $\mathrm{SO}_{\mathrm{x}}$, leading to $\pm 1 \sigma$ variance in total deposition fluxes of about $30 \%$ in the anthropogenic emissions regions, and up to a factor of 2 outside. In all cases the mean model constructed from the ensemble calculations is among the best when comparing to measurements. Currently, $36-51 \%$ of all $\mathrm{NO}_{\mathrm{y}}, \mathrm{NH}_{\mathrm{x}}$, and $\mathrm{SO}_{\mathrm{x}}$ is deposited over the ocean, and $50-80 \%$ of the fraction of deposition on land falls on natural (nonagricultural) vegetation. Currently, $11 \%$ of the world's natural vegetation receives nitrogen deposition in excess of the "critical load" threshold of $1000 \mathrm{mg}(\mathrm{N}) \mathrm{m}^{-2} \mathrm{yr}^{-1}$. The regions most affected are the United States $(20 \%$ of vegetation), western Europe (30\%), eastern Europe (80\%), South Asia (60\%), East Asia

\footnotetext{
${ }^{1}$ European Commission, Institute for Environment and Sustainability, Joint Research Centre, Ispra, Italy.

${ }^{2}$ Swiss Federal Institute of Technology (EPFL), Lausanne, Switzerland.

${ }^{3}$ Atmospheric Chemistry Division, National Center of Atmospheric Research, Boulder, Colorado, USA.

${ }^{4}$ Netherlands Environmental Assessment Agency (RIVM), Bilthoven, Netherlands.

${ }^{5}$ Geophysical Fluid Dynamics Laboratory, NOAA, Princeton, New Jersey, USA.

${ }^{6}$ Laboratoire des Sciences du Climat et de l'Environnement, CEA/ CNRS, Gif-sur-Yvette, France.

${ }^{7}$ Now at Space Research Organisation Netherlands (SRON), Utrecht, Netherlands.

${ }^{8}$ Also at Wageningen University and Research Center (WUR), Wageningen, Netherlands.

${ }^{9}$ Analytical and Environmental Chemistry Division, Indian Institute of Chemical Technology, Hyderabad, India.

${ }^{10}$ Max Planck Institute for Chemistry, Mainz, Germany.

${ }^{11}$ Laboratoire d'Aérologie, Observatoire Midi-Pyrénées, Toulouse, France.

${ }^{12}$ Max Planck Institute for Meteorology, Hamburg, Germany.

Copyright 2006 by the American Geophysical Union. 0886-6236/06/2005GB002672
}

${ }^{13}$ NASA-Goddard Institute for Space Studies, New York, USA.

${ }^{14}$ School of Geosciences, Institute for Atmospheric and Environmental Science, University of Edinburgh, UK.

${ }^{15}$ Atmospheric Composition, Climate Research and Seismology Department, Royal Netherlands Meteorological Institute (KNMI), De Bilt, Netherlands.

${ }^{16}$ Atmospheric Science Division, Lawrence Livermore National Laboratory, Livermore, California, USA.

${ }^{17}$ International Institute for Applied Systems Analysis (IIASA), Laxenburg, Austria.

${ }^{18}$ Met Office, Exeter, UK.

${ }^{19}$ Department of Geosciences, University of Oslo, Oslo, Norway.

${ }^{20}$ Department of Environmental Sciences, University of Virginia, Charlottesville, Virginia, USA.

${ }^{21}$ Dipartimento di Fisica, Università L'Aquila, Aquila, Italy.

${ }^{22}$ Belgian Institute for Space Aeronomy, Brussels, Belgium.

${ }^{23}$ Goddard Earth Science and Technology Center (GEST), Baltimore, Maryland, USA.

${ }^{24}$ Now at ICG-II, Jülich, Germany.

${ }^{25}$ Atmospheric Composition Research Program, Frontier Research Center for Global Change (JAMSTEC), Yokohama, Japan.

${ }^{26}$ Now at Centre of Atmospheric Science, University of Cambridge, Cambridge, UK. 
(40\%), southeast Asia (30\%), and Japan (50\%). Future deposition fluxes are mainly driven by changes in emissions, and less importantly by changes in atmospheric chemistry and climate. The global fraction of vegetation exposed to nitrogen loads in excess of $1000 \mathrm{mg}(\mathrm{N}) \mathrm{m}^{-2} \mathrm{yr}^{-1}$ increases globally to $17 \%$ for CLE and $25 \%$ for A2. In MFR, the reductions in $\mathrm{NO}_{\mathrm{y}}$ are offset by further increases for $\mathrm{NH}_{\mathrm{x}}$ deposition. The regions most affected by exceedingly high nitrogen loads for CLE and A2 are Europe and Asia, but also parts of Africa.

Citation: Dentener, F., et al. (2006), Nitrogen and sulfur deposition on regional and global scales: A multimodel evaluation, Global Biogeochem. Cycles, 20, GB4003, doi:10.1029/2005GB002672.

\section{Introduction}

[2] Reactive nitrogen $\mathrm{Nr}\left(\mathrm{NO}_{\mathrm{y}}, \mathrm{NH}_{\mathrm{x}}\right)$ plays a central role in the chemistry of the atmosphere as well as in the productivity of marine, freshwater and terrestrial ecosystems. There is a host of evidence that increasing human activities seriously disturb the natural nitrogen cycle [Galloway et al., 2004; Phoenix et al., 2006; Vitousek et al., 1997]. Nr enters the environment through a number of processes related to fertilization, waste discharge and atmospheric emissions.

[3] Nitrogen oxide (NO) is emitted into the atmosphere by natural processes such as lightning or soil emissions, and by human activities related to power generation, industry, traffic and open biomass burning. In the atmosphere NO is converted into a number of other oxides of nitrogen, generally denominated as $\mathrm{NO}_{\mathrm{y}}$ (in this work $\mathrm{NO}_{\mathrm{y}}=\mathrm{NO}+$ $\mathrm{NO}_{2}+\mathrm{HNO}_{3}+\mathrm{HNO}_{4}+\mathrm{NO}_{3}+2 \mathrm{xN}_{2} \mathrm{O}_{5}+\mathrm{PAN}+$ organic nitrates). $\mathrm{NO}$ emissions can lead to the formation of ozone in both the background troposphere [Crutzen, 1974] as well as in rural environments [Finlayson-Pitts and Pitts, 1986], with detrimental effects for human health [World Health Organization, 2003], natural vegetation and agricultural crops [Emberson et al., 2000; Mauzerall and Wang, 2001]. In addition, NO emissions influence the oxidation capacity of the atmosphere [Lelieveld et al., 2002; Wang and Jacob, 1998].

[4] The alkaline gas ammonia $\left(\mathrm{NH}_{3}\right)$ is predominantly emitted from agricultural sources and reacts readily in the atmosphere with sulfuric acid $\left(\mathrm{H}_{2} \mathrm{SO}_{4}\right)$, nitric acid $\left(\mathrm{HNO}_{3}\right)$ and other acids, to form particulate ammonium $\left(\mathrm{NH}_{4}\right)$. Ammonium influences the abundance, composition and radiative properties of aerosol and its climatic impact [Metzger et al., 2002]. The sum of $\mathrm{NH}_{3}+\mathrm{NH}_{4}$ is generally referred to as $\mathrm{NH}_{\mathrm{x}}$. Since the chemistry of ammonia is closely connected to that of sulfate $\left(\mathrm{SO}_{4}\right)$, an integral part of our study involves the analysis of the sulfur dioxide $\left(\mathrm{SO}_{2}\right)$ emissions and $\mathrm{SO}_{\mathrm{x}}\left(=\mathrm{SO}_{2}+\mathrm{SO}_{4}\right)$ deposition.

[5] The ultimate fate of the $\mathrm{NO}_{\mathrm{y}}, \mathrm{NH}_{\mathrm{x}}$ and $\mathrm{SO}_{\mathrm{x}}$ is removal by wet scavenging and dry deposition on terrestrial and aquatic ecosystems. Deposition of reactive nitrogen induces a cascade of environmental effects [Galloway et al., 2004]. Since the net primary production of most terrestrial ecosystems is limited by nitrogen availability, deposition of reactive nitrogen may enhance ecosystem productivity [Vitousek et al., 1997] with possible consequences for the global carbon cycle [Prentice et al., 2001]. On the other hand, eutrophication by $\mathrm{Nr}$ can cause acidification [Rodhe et al., 2002], an imbalance in nutrient cycling leading to a change of ecosystem diversity [Bobbink et al., 1998; Phoenix et al., 2006; Sala et al., 2000], as indicated by the exceedance of critical loads [Bobbink et al., 1998; Bouwman et al., 2002b]. In fresh water and coastal regions, nitrogen inputs can lead to noxious and toxic algal blooms, increased turbidity, and disruption of ecosystem functioning, shifts in food webs and loss of fish stocks [Rabalais, 2002]. Nitrogen deposition to coastal waters leads to denitrification and enhanced emissions of $\mathrm{N}_{2} \mathrm{O}$, which is in turn a strong greenhouse gas and perturbs the chemistry of the stratosphere [Seitzinger and Kroeze, 1998].

[6] Owing to increasing anthropogenic activities, such as the use of fossil fuels and agricultural production, the global emissions of $\mathrm{NO}, \mathrm{NH}_{3}$ and $\mathrm{SO}_{2}$ may have increased by more than a factor of 3 since the preindustrial era. Regionally, these increases have been even more substantial and emissions from large portions of North America, Europe and Asia increased by more than a factor of 10 during the last century [Aardenne et al., 2001]. Recent studies [Galloway et al., 2004; Lamarque et al., 2005; Nakicenovic et al., $2000]$ indicate substantial further increases of emissions and deposition toward 2050 and 2100.

[7] In this work we focus on nitrogen and sulfur deposition in the year 2030 using a new set of emission scenarios for $\mathrm{NO}_{\mathrm{x}}, \mathrm{SO}_{2}, \mathrm{CH}_{4}$, and $\mathrm{CO}$ recently developed at IIASA (International Institute for Applied Systems Analysis) and described by Dentener et al. [2005, and references therein]. The scenarios differ substantially from the previous SRES [Nakicenovic et al., 2000] scenarios, since they address concerns about the environmental impacts of the rapid growing economies of countries in Asia and Latin America. Therefore in the early 2000 s a number of countries have issued legislation on advanced emission controls, which can significantly cap the air pollution emissions at the regional and global scales. This is the basis of our CLE (Current LEgislation) scenario. Further, we evaluate the effects of the emissions of a MFR (Maximum technologically Feasible Reduction) scenario. To illustrate the situation of rapid economic growth paired with no further controls on air pollutant emissions, we also use the SRES A2 scenario. Both CLE and MFR are based on economic developments consistent with the moderate SRES B2 scenario. For $\mathrm{NH}_{3}$, IIASA and IPCC-SRES have no emission scenarios available. We used the RIVM-IMAGE regional assumptions on population increase and agricultural developments from the SRES A2 and B2 scenarios, to make a separate estimate for the development of $\mathrm{NH}_{3}$ emissions.

[8] These emission scenarios were used by a large set of global atmospheric chemistry-transport (CTMs) and general 
Table 1. Overview of Simulations and Global Annual Anthropogenic Emissions (Including Biomass Burning) of $\mathrm{NO}_{\mathrm{x}}, \mathrm{NH}_{3}, \mathrm{SO}_{2}, \mathrm{CO}$ and NMVOC

\begin{tabular}{|c|c|c|c|c|c|c|c|}
\hline Simulation & Meteorology & Description & $\mathrm{NO}_{\mathrm{x}} \mathrm{Tg} \mathrm{N}$ & $\mathrm{NH}_{3} \mathrm{Tg} \mathrm{N}$ & $\mathrm{SO}_{2} \mathrm{Tg} \mathrm{S}$ & $\mathrm{CO} \mathrm{Tg} \mathrm{CO}$ & NMVOC Tg NMVOC \\
\hline S1-B2000 & $\begin{array}{l}\text { CTM } 2000 \\
\quad \text { GCM SSTs 1990s }\end{array}$ & baseline & 38.0 & 53.4 & 55.6 & 977.0 & 147.1 \\
\hline S2-CLE/CLEc & $\begin{array}{l}\text { CTM } 2000 \\
\quad \text { GCM SSTs 1990s }\end{array}$ & $\begin{array}{l}\text { IIASA CLE } 2030 \\
\text { Current Legislation scenario }\end{array}$ & 42.9 & 69.8 & 58.8 & 904.1 & 145.5 \\
\hline S3-MFR & $\begin{array}{l}\text { CTM } 2000 \\
\quad \text { GCM SSTs 1990s }\end{array}$ & $\begin{array}{l}\text { IIASA MFR } 2030 \text { Maximum } \\
\text { Feasible Reduction scenario }\end{array}$ & 23.3 & 69.8 & 17.9 & 728.7 & 104.4 \\
\hline S4-A2 & $\begin{array}{l}\text { CTM } 2000 \\
\quad \text { GCM SSTs 1990s }\end{array}$ & $\begin{array}{l}\text { SRES A22030, the most } \\
\text { "pessimistic" IPCC SRES scenario }\end{array}$ & 64.8 & 74.3 & 101.1 & 1268.2 & 206.7 \\
\hline S5c-CLE2030c & $\begin{array}{l}\text { only GCM SSTs } \\
2030 \mathrm{~s}\end{array}$ & IIASA CLE $2030+$ climate change & 42.9 & 69.8 & 58.8 & 904.1 & 145.5 \\
\hline
\end{tabular}

circulation models (GCMs) to evaluate present and future (2030) ozone air quality, ecosystem exposure to nitrogen/ acid deposition, and impacts of climate change on atmospheric chemistry. Detailed results on these aspects can be found in a series of publications recently published or in press [Dentener et al., 2006; Stevenson et al., 2006; van Noije et al., 2006; Shindell et al., 2006] or in preparation (K. Ellingsen et al., Ozone air quality in 2030: A multimodel assessment of risks for health and vegetation, manuscript in preparation, 2006). This paper evaluates nitrogen and sulfur deposition in the present and in future, analyzing both intermodel and interscenario differences.

[9] In section 2 we will describe the set-up of the model experiment, give model characteristics, and describe the input emissions. In section 3.1 we will give an evaluation of the current ability of models to calculate wet deposition, with an emphasis on what we can learn from the multimodel approach. Section 3.2 describes how deposition changes in the future, and how this may impact regional and ecosystem specific deposition. In section 4 we present the discussion and concluding remarks. This manuscript is accompanied by auxiliary material ${ }^{1}$ containing additional information and analyses.

\section{Simulations, Models, and Emissions}

[10] Of the 26 models participating in the ACCENT IPCC-AR4 modeling exercise, 23 models labeled A-W, submitted deposition calculations (Table ts01). Some of these models share common modules and/or meteorological input data. In this work, we treat each model with equal weight. One model had a resolution of $1^{\circ} \times 1^{\circ}$ in North America, Europe and Asia, 9 models had resolutions between $2^{\circ} \times 2^{\circ}$ and $3^{\circ} \times 3^{\circ} ; 12$ models had a grid spacing of around $5^{\circ} \times 5^{\circ}$, and one model had a resolution of $23.5^{\circ} \times 10^{\circ}$ (longitude $\times$ latitude). Of the 23 models, 10 models included the tropospheric sulfur cycle, and 7 models included $\mathrm{NH}_{\mathrm{x}}$ chemistry. Up to five simulations were performed by each model (Table 1 and Table 2). S1-B2000 evaluated the reference year 2000, whilst S2-CLE, S3-MFR, and S4-A2 assessed the year 2030. CTMs used the meteorological year 2000. GCMs performed typically 5-10 years of simulations, using a climate appropriate for the time period 1995-2004. To evaluate

\footnotetext{
${ }^{1}$ Auxiliary material data sets are available at ftp://ftp.agu.org/apend/ 2005gb002672. Other auxiliary material files are in the HTML.
}

the impacts of climate change, an additional simulation (S5-CLE2030c) was computed by 10 of the GCM-driven models, using various projections of climate appropriate for 2030, corresponding to a global mean surface warming of about $0.7 \mathrm{~K}$ between 2000 and 2030. Global anthropogenic emissions of $\mathrm{SO}_{2}$ and $\mathrm{NO}$ were generated by IIASA, and spatially distributed using the EDGAR3.2 database [Dentener et al., 2005]. $\mathrm{NH}_{3}$ emissions were calculated using the agricultural and land-use modules of the Earth system model IMAGE2.2 [Eickhout et al., 2004] and spatially distributed using the Bouwman et al. [2002a] global ammonia $\mathrm{NH}_{3}$ inventory. Only two $\mathrm{NH}_{3}$ emissions scenarios were generated using the assumptions made regarding economical and agricultural developments in the SRES B2 and A2 scenarios. For simplicity we group the B2 scenario together with the IIASA CLE scenario. Since thus far no realistic MFR analysis for worldwide $\mathrm{NH}_{3}$ emission reduction potentials has been made, we also used the $\mathrm{B} 2$ emissions for our MFR (S3) scenarios, but we do not focus on these results. Ship and aircraft emissions were also included in this study; however, no separate estimate for the MFR and A2 scenario was made. Aircraft emissions followed the IPCC aircraft scenario described by Isaksen et al. [1999]. Ship emissions in all three scenarios included an assumed global increase of $1.5 \% \mathrm{yr}^{-1}$ (resulting in a 70\% increase by 2030), without assuming improvements of engine performance. A recent evaluation of present and future ship emissions [Eyring et al., 2005] shows large uncertainty in the estimates of current emissions, and a larger possible range of future emissions due to technological developments.

[11] In this exercise we assumed that biomass burning emissions remained constant between 2000 and 2030. We took the $\mathrm{CO}$ emissions from the Global Fire Emissions Dataset GFED1.0 [Van der Werf et al., 2003] averaged for the years 1997-2002, and scaled them with the ecosystem specific emissions factors for other components compiled by Andreae and Merlet [2001]. Note here that a recent revision of that database (A. Andreae, personal communication, 2005) indicates lower emissions for NO from savannah fires, which was not included in this work. All models also included natural emissions, for which global source strengths were recommended. However, since models often calculate natural emissions, we did not provide specific emission data sets. Some of the climate models included a (small) feedback of climate on these natural emissions. Probably the only relevant climate-emission feedback included in some models involves lightning, 
which we will analyze in section 3.5. In Table 1 we present the global emissions of $\mathrm{NO}, \mathrm{NH}_{3}$, and $\mathrm{SO}_{2}, \mathrm{CO}$ and NMVOC for each scenario, while regional and sectoral breakdown of the anthropogenic $\mathrm{NO}, \mathrm{NH}_{3}$, and $\mathrm{SO}_{2}$ emissions for the year 2000, and the development of the total emissions for the 3 scenarios are presented and discussed in auxiliary Tables ts 02 , ts 03 , and ts 04 .

\section{Results}

[12] We start in section 3.1 with an evaluation of the ability of the models to calculate current wet deposition. We focus on wet deposition since a fair amount of data are available worldwide. Dry deposition is an equally important process to remove nitrogen and sulfur species. Some observations relevant to derive dry deposition are available in, for example, North America and Africa. However, the analysis of these measurements would involve a careful analysis of aerosol and gas surface concentrations and dry deposition parameterizations in the models and would not have a global coverage. Therefore it is beyond the scope of this manuscript. In section 3.2 and 3.3 we analyze current and future total deposition. Section 3.4 deals with the role of climate change, whereas 3.5 concerns ecosystem specific deposition. Model results of individual models were interpolated to $1^{\circ} \times 1^{\circ}$ for further analysis. We calculated per $1^{\circ} \times 1^{\circ}$ grid box the mean, median and standard deviation from the individual model results. In the following we call this the "mean" and "median" model. We will show that there is very little difference in the mean and median model results, and in section 3.2 and further we will mainly use the mean model results.

\subsection{Evaluation of Current Wet Deposition}

[13] We evaluate the annual average wet deposition of all models, and most results pertain to the mean of these models. Results for individual models are available at http://ccupeople.jrc.it/dentener/index.htm. For North America we used wet-only deposition measurements for 2000 of the North American Deposition Program (NADP) network available through the internet (http://nadp.sws.uiuc.edu/). For Europe we use wet-only deposition measurements for 2000 from EMEP (http://www.nilu.no/projects/ccc/ emepdata.html). For Africa we use the deposition data from the IDAF (Igac Debits Africa) program (http://medias. obs-mip.fr/idaf). Of the eight available stations, four stations had measurements for the year 2000, but only one of them (Niger) had reliable measurements. For the other four stations we included a multiannual average representative for 1996-1999. IDAF data are described in various publications [Galy-Lacaux et al., 2003; Jaeglé et al., 2004]. For East Asia we obtained data from the recently established Acid Deposition Monitoring Network in East Asia [EANET, 2001] for the year 2000. The complete network consists of 46 stations, 9 in China, 10 in and around Japan, 4 in Indonesia, and 1-3 stations in Malaysia, Mongolia, the Philippines, Korea, Asian Russia, Thailand and Vietnam. We selected the regional and remote stations and ignored the data that were reported not to meet EANET quality checks. Some very high $\mathrm{SO}_{4}$ rain-water concentrations were correlated with high concentrations of $\mathrm{Ca}$. Since a significant fraction of the $\mathrm{CaSO}_{4}$ may originate from the dust-source regions [Grassian, 2001], we ignored $\mathrm{SO}_{4}$ deposition measurements coinciding with calcium deposition larger than $20 \mathrm{mmolm}^{-2} \mathrm{yr}^{-1}$. However, we cannot exclude that part of the $\mathrm{SO}_{4}$ was derived from anthropogenic emissions, mixed with natural dust. We complemented the EANET data with five stations from the IMPACT (Integrated Monitoring program on acidification of terrestrial Ecosystems) network in China for 2001-2003 [Larsen et al., 2004].

[14] For India we used the precipitation chemistry compilation of Kuhlshrestha et al. [2005]. The data set spans about 100 stations, of which we used the 50 stations which were characterized as "rural" and "sub-urban." We discarded "urban" and "industrial" measurements since they are not representative for the coarse resolution models used in this study. Only few stations operated wet-only measurements. Most data apply to the $1995-2000$ period. Very few publications reveal their QA procedures. We will see later that our models seriously overestimate measured $\mathrm{NH}_{4}$ deposition and we can not exclude that in many cases sample degradation may have lead to an underestimate of $\mathrm{NH}_{4}$ in the measurements.

[15] For South America we used a variety of data for various years described by Dentener and Crutzen [1994] and Whelpdale et al. [1997] supplemented with the more recent measurements reported by Filoso et al. [1999] and Lara et al. [2001]. Altogether we report on South American wet deposition measurements in 17 locations. Given the heterogeneity of data sources, we expect that data quality and representativeness are important issues.

[16] Finally, to evaluate worldwide background deposition, we used the set of 11 stations described in more detail by J. N. Galloway et al. (Atmospheric wet deposition in remote regions: Benchmarks for change, manuscript in preparation, 2006). Data covered the period 1980-1999. For this work we made multiannual averages. Measurement locations are mostly background locations on remote islands, Australia and South America.

[17] In Figures 1, 2, and 3 we display scatter plots of the mean model $\mathrm{NO}_{3}, \mathrm{NH}_{4}$ and $\mathrm{SO}_{4}$ wet deposition for four networks in Europe, North America, East Asia, and Africa, respectively. The model $\mathrm{NO}_{3}$ deposition contains the contribution of gas phase $\mathrm{HNO}_{3}$ and aerosol nitrate (the latter only for the models that included aerosol nitrate). The model $\mathrm{SO}_{4}$ contains the wet $\mathrm{SO}_{4}$ and $\mathrm{SO}_{2}$ deposition (assuming that in the rainwater dissolved $\mathrm{SO}_{2}$ gets oxidized). Model $\mathrm{NH}_{4}$ deposition contains the sum of aerosol $\mathrm{NH}_{4}$ and gas phase $\mathrm{NH}_{3}$ wet deposition. Similar plots are available at http://ccupeople.jrc.it/dentener/resultsIPCC meas.htm for all models and all regions under consideration. A summary of the statistical analysis for all regions and the mean/median model is presented in auxiliary Tables ts 05 , ts06 and ts07 for $\mathrm{NO}_{3}, \mathrm{NH}_{4}$, and $\mathrm{SO}_{4}$ deposition, respectively. Figure 1 shows that the mean model convincingly represents $\mathrm{NO}_{3}$ deposition in Europe, North America and Africa, and East Asia; $70-80 \%$ of the mean model results agree within $\pm 50 \%$ with the observations. The mean model underestimates $\mathrm{NO}_{3}$ deposition in South and East Asia, and somewhat overestimates in Africa (auxiliary Table ts05). 

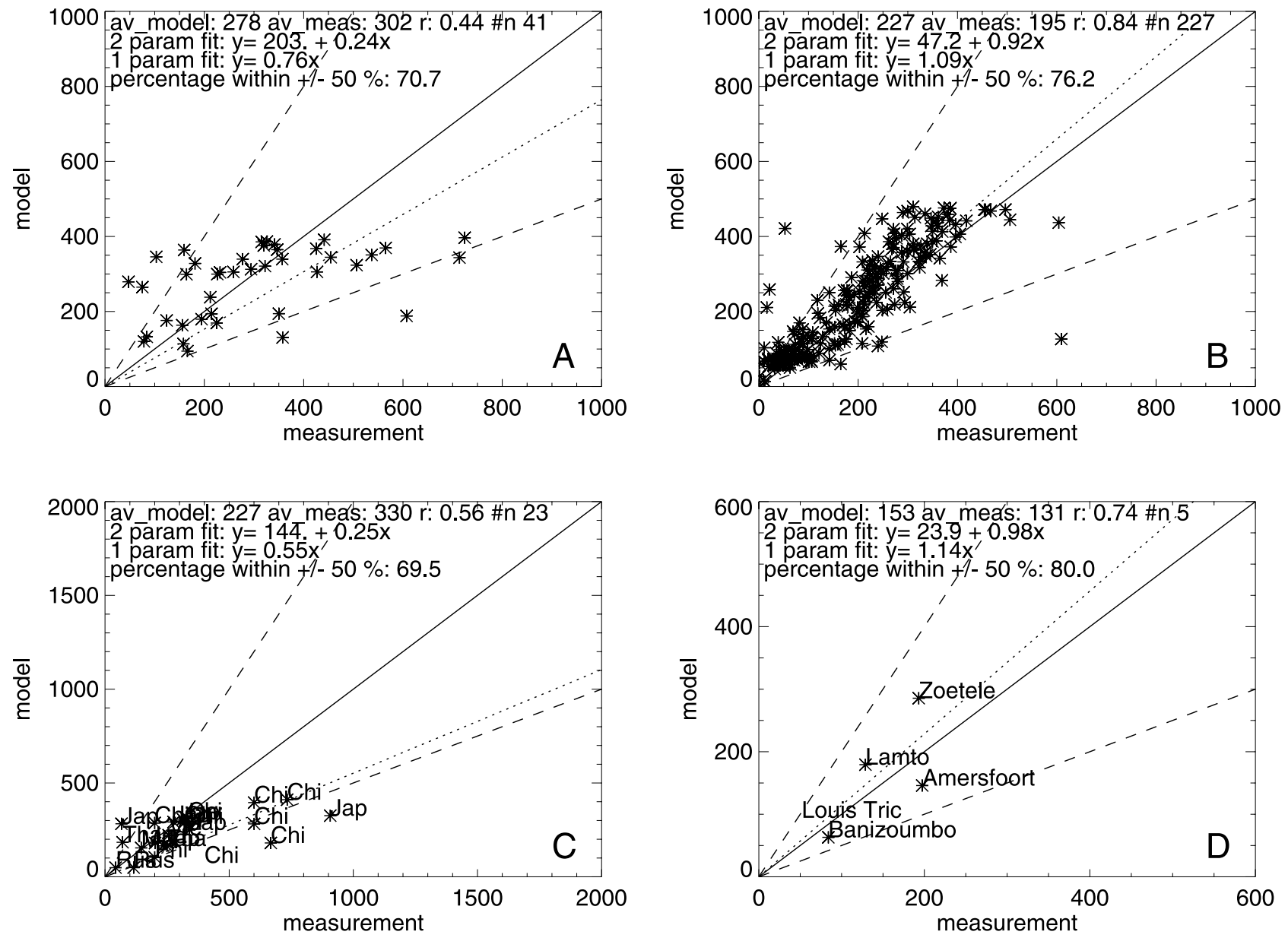

Figure 1. Scatterplots for simulation $\mathrm{S} 1$ of nitrate $\left(\mathrm{HNO}_{3}\right.$ and aerosol nitrate) wet deposition of the mean model versus measurements for four networks in (a) Europe, (b) North America, (c) East Asia, and (d) Africa. Dashed lines indicate \pm factor 1:2 and 2:1. The dotted line is the result of linear regression fitting through 0 .

Also $\mathrm{NH}_{4}$ is rather well modeled in those four regions (Figure 2); however, in East Asia, $\mathrm{NH}_{4}$ is somewhat underestimated. In South Asia (India) $\mathrm{NH}_{4}$ deposition is strongly overestimated by on average $350 \mathrm{mg}(\mathrm{N}) \mathrm{m}^{-2} \mathrm{yr}^{-1}$ (auxiliary Table ts06). This overestimate could be simply related to an overestimate of the highly uncertain $\mathrm{NH}_{3}$ emissions in India. Alternatively, the measured $\mathrm{NH}_{4}$ could be underestimated owing to biological degradation of unstabilized samples. An additional likely explanation for the underestimate is the interaction of dust and sulfate which may neutralize sulfate and reduce the ammonium sulfate formation.

[18] This important aerosol interaction was not included in the models participating in this exercise. Good agreement is found for $\mathrm{SO}_{4}$ deposition in North America, Europe and Africa (Figure 3), but not for Southeast and East Asia. The disagreement would be even larger had we used the $\mathrm{SO}_{4}$ deposition fluxes in high dust deposition regions. A possible explanation could be that the sulfur emission factors for coal burning in China are too low, and/or unaccounted sources from small industrial activities. Note that $\mathrm{SO}_{2}$ emissions in China in this study are higher by $40 \%$ compared to the widely used TRACE-P inventory for 2000 [Streets et al., 2003].
[19] The question now arises as to how representative the mean or median model are for the set of model simulations in our study. To answer this question we display in Figure 4 and auxiliary Figures fs 02 and fs 03 the spatial correlation coefficient (" $r$ ") of the annual wet deposition of all models and measurements and their spatial standard deviation for $\mathrm{NO}_{\mathrm{y}}, \mathrm{SO}_{\mathrm{x}}$, and $\mathrm{NH}_{\mathrm{x}}$ for the four networks in Europe, North America, East Asia, and Africa. In our study we used standard deviation defined as

$$
s d=\sqrt{\sum_{i=1}^{n} \frac{\left(x_{i}-\operatorname{mean}(x)\right)^{2}}{n-1} .}
$$

These so-called Taylor [2001] plots then give the "best" model as the shortest distance to the observation. The mean represents the region average of the annual deposition at $n$ stations. The best agreement between modeled and measured $\mathrm{NO}_{3}$ wet deposition is found in North America (Figure 4), corresponding to spatial correlation coefficients of around 0.8 and spatial standard deviations of models similar to those measured. The correlation in Europe (EMEP) is for most models around 0.6, with an under- 

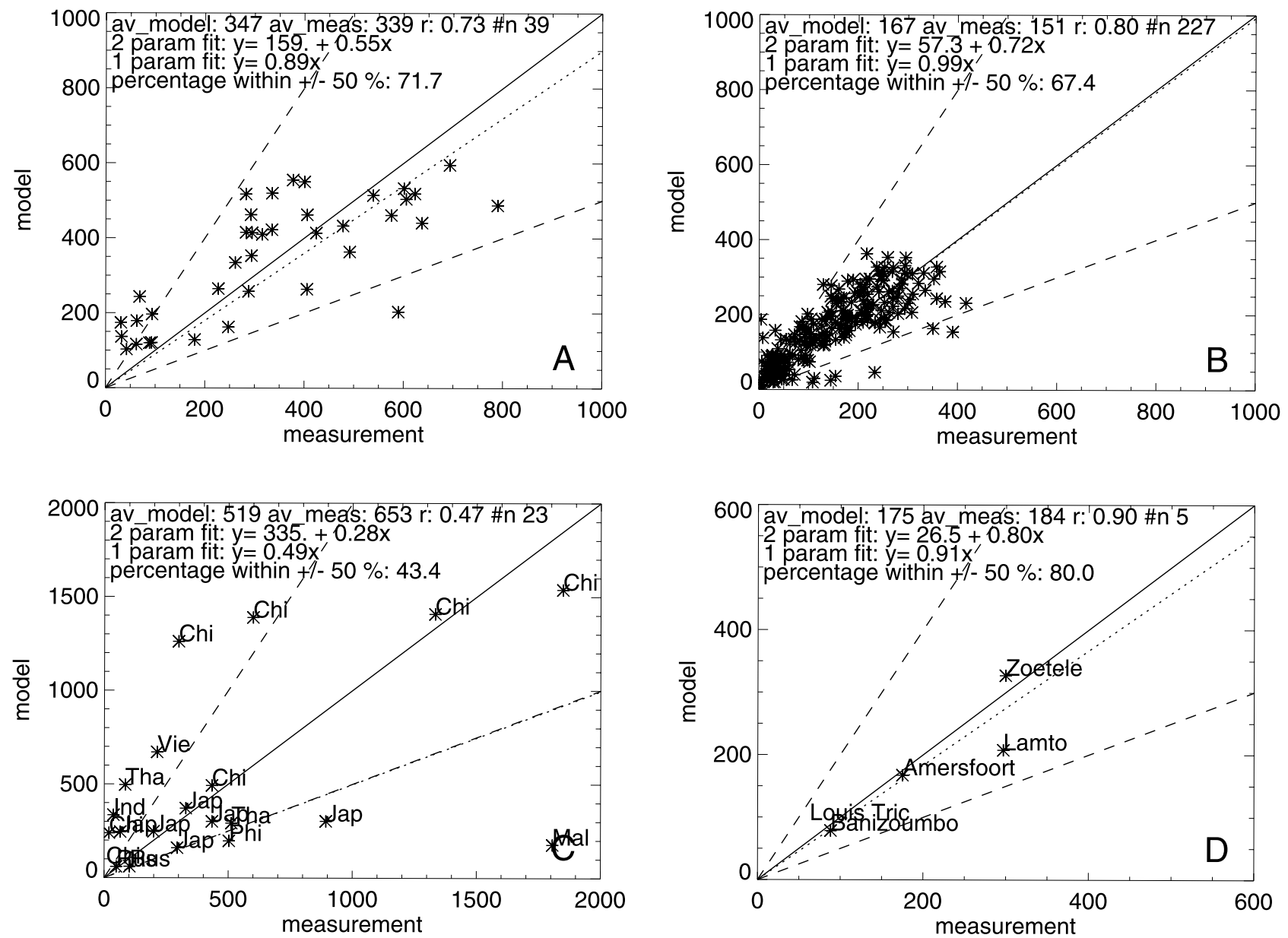

Figure 2. As in Figure 1 for ammonium wet deposition.

estimate of spatial variability in most models, except for those with relatively high spatial resolutions (e.g., A, B, T and $\mathrm{U}$; for model codes see auxiliary Table S1). This result is remarkably better than found by Lamarque et al. [2005], who report correlation coefficients of $0.2-0.4$. We explain the difference from the fact that in this study we used an upto-date emission dataset for the year 2000, whereas in the Lamarque et al. [2005] study, older emission data sets were used. In Southeast Asia (EANET) and Africa spatial correlations are generally between 0.4 and 0.6 , together with an underestimate of measured spatial variability. The "mean" and "median" models are generally among the best of the set model simulations, but never superior to the best single model result for a specific region. Auxiliary Figure fs02 shows that the model-and measurement deviations of the short-lived component $\mathrm{NH}_{\mathrm{x}}$ is generally larger than those of $\mathrm{NO}_{3}$ with a high correlation in Europe and North America and, as expected, an underestimate of the spatial variability. For $\mathrm{SO}_{4}$ in North America, Europe and Africa (auxiliary Figure fs03) we see a similar picture, along with the strong underestimate of calculated $\mathrm{SO}_{4}$ deposition by all models in East Asia. No single model could represent the measurements and underestimates of wet $\mathrm{SO}_{4}$ deposition were found throughout Asia, which strongly indicates shortcomings in the $\mathrm{SO}_{2}$ emissions estimates.
[20] In Figures $5 \mathrm{a}-5 \mathrm{c}$ we present a synthesis of worldwide modeled and measured wet deposition, by averaging all measurements that were obtained in a $10^{\circ}$ longitude $\times 5^{\circ}$ latitude region and plotting it on the calculated deposition. This presentation highlights that the worldwide deposition patterns of $\mathrm{NO}_{3}, \mathrm{NH}_{4}$, and $\mathrm{SO}_{\mathrm{x}}$ are well represented in our mean model. In general modeled $\mathrm{NO}_{3}$ deposition agrees within $\pm 100 \mathrm{mg}(\mathrm{N}) \mathrm{m}^{-2} \mathrm{yr}^{-1}$ with measurements. The deviations of $\mathrm{NH}_{4}$ deposition with measurements in South Asia (India) is apparent in Figure 5b, but otherwise $\mathrm{NH}_{4}$ deposition agrees relatively well with observations. The modeled and measured $\mathrm{SO}_{4}$ deposition seems fairly consistent. However, as indicated before, there are serious model underestimates of $\mathrm{SO}_{4}$ deposition in Asia, which are not obvious in Figure 5c.

\subsection{Present Deposition}

[21] Whereas in the previous section we evaluated the wet deposition calculations, in this section we focus on the total (wet + dry) deposition of $\mathrm{NO}_{\mathrm{y}}, \mathrm{NH}_{\mathrm{x}}, \mathrm{SO}_{\mathrm{x}}$, and total reactive nitrogen $\mathrm{Nr}$ for the present and future scenarios.

\subsubsection{Global Budgets of $\mathrm{NO}_{\mathbf{y}}, \mathrm{NH}_{\mathbf{x}}$, and $\mathrm{SO}_{\mathbf{x}}$} Deposition

[22] A comparison of the global deposition budgets for the individual models is presented in auxiliary Figure fs 05. 

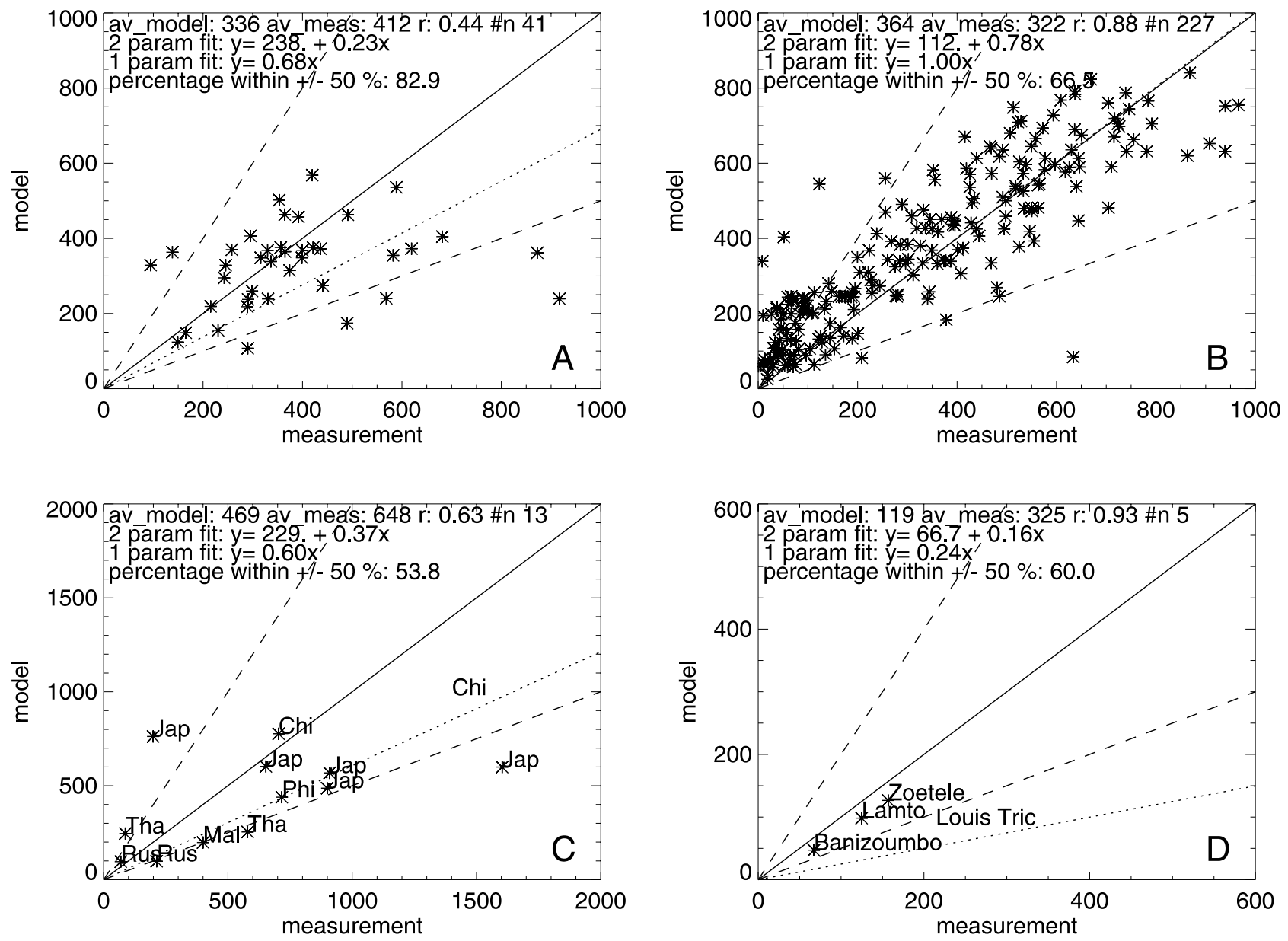

Figure 3. As in Figure 1 for sulfate wet deposition.

The spread $( \pm 1 \sigma)$ of about $6 \%, 8 \%$, and $10 \%$ in the total global model deposition of $\mathrm{NO}_{\mathrm{y}}, \mathrm{NH}_{\mathrm{x}}$, and $\mathrm{SO}_{\mathrm{x}}$, respectively, gives an indication of the global variability of natural emissions among models. We note here that although we gave recommendations on the source strength of natural emissions, most models used their own parameterizations to calculate, for example, oceanic DMS, lightning, and soil $\mathrm{NO}_{\mathrm{x}}$ emissions. To gain insight into the relative importance of dry and wet deposition in our calculations we present in auxiliary Figure fs06 for all models the ratio of global wet to total $\mathrm{NO}_{\mathrm{y}}, \mathrm{NH}_{\mathrm{x}}$, and $\mathrm{SO}_{\mathrm{x}}$ deposition, respectively. The relative importance of wet and dry deposition for removal of $\mathrm{NO}_{\mathrm{y}}$ varies significantly among models. Globally, between $40 \%$ and $70 \%$ of $\mathrm{NO}_{\mathrm{y}}$ (auxiliary Figure fs06a) is removed by wet deposition. The models are remarkably consistent regarding the importance of gaseous $\mathrm{HNO}_{3}$ and aerosol- $\mathrm{NO}_{3}$ deposition, accounting for 80 $90 \%$ of all $\mathrm{NO}_{\mathrm{y}}$ deposition (auxiliary Figure fs06b). The remainder is deposition of $\mathrm{NO}_{2}$ and organic nitrates. For $\mathrm{NH}_{\mathrm{x}}$ (auxiliary Figure fs06c) the fraction of wet deposition ranges hugely among models, from less than $40 \%$ to more than $80 \%$. The assumptions used in various models regarding the $\mathrm{NH}_{3}$ dry deposition velocity, and the atmospheric chemistry of $\mathrm{NH}_{4}$ formation, are causing these differences. Also, model mixing characteristics and resolution are likely to be important for the $\mathrm{NH}_{\mathrm{x}}$ budget. Finally, relatively consistent among models, wet deposition contributes between 50 and $70 \%$ to the total global $\mathrm{SO}_{\mathrm{x}}$ deposition.

[23] There are small differences in the ratio of wet to total deposition for scenarios S2-S5; for instance, most models predict a larger fraction of $\mathrm{NO}_{\mathrm{y}}$ removed by wet deposition in scenario S3-MFR compared to S1-B2000 and a somewhat lower fraction when comparing S4-A1 and S1-B2000. These changes in the global budgets can be explained by the dissimilar interaction of emissions, chemistry, and meteorology in various parts of the world contributing differently in the various scenarios. Note that meteorology (e.g., precipitation) in simulations $\mathrm{S} 1-\mathrm{S} 4$ was prescribed so that the wet and dry removal rates were unchanged in simulations $\mathrm{S} 1-\mathrm{S} 4$. Differences in the global removal processes of S5-CLEc and S2-CLE are also small and will be further discussed in section 3.4.

[24] How different are the models results on regional scales and what is the role of model resolution? To illustrate this we present in Figures $6 a-6 c$ the calculated wet, dry and total $\mathrm{NO}_{\mathrm{y}}$ deposition $\left[\mathrm{Tg}(\mathrm{N}) \mathrm{yr}^{-1}\right]$ of all models over the eastern part of Asia $\left(20^{\circ} \mathrm{N}-45^{\circ} \mathrm{N} ; 110^{\circ} \mathrm{E}-130^{\circ} \mathrm{E}\right)$, separating the deposition over land and over sea. We assume here that to a large extent the eastern Asian budget is closed meaning that the emissions over eastern Asia should be 

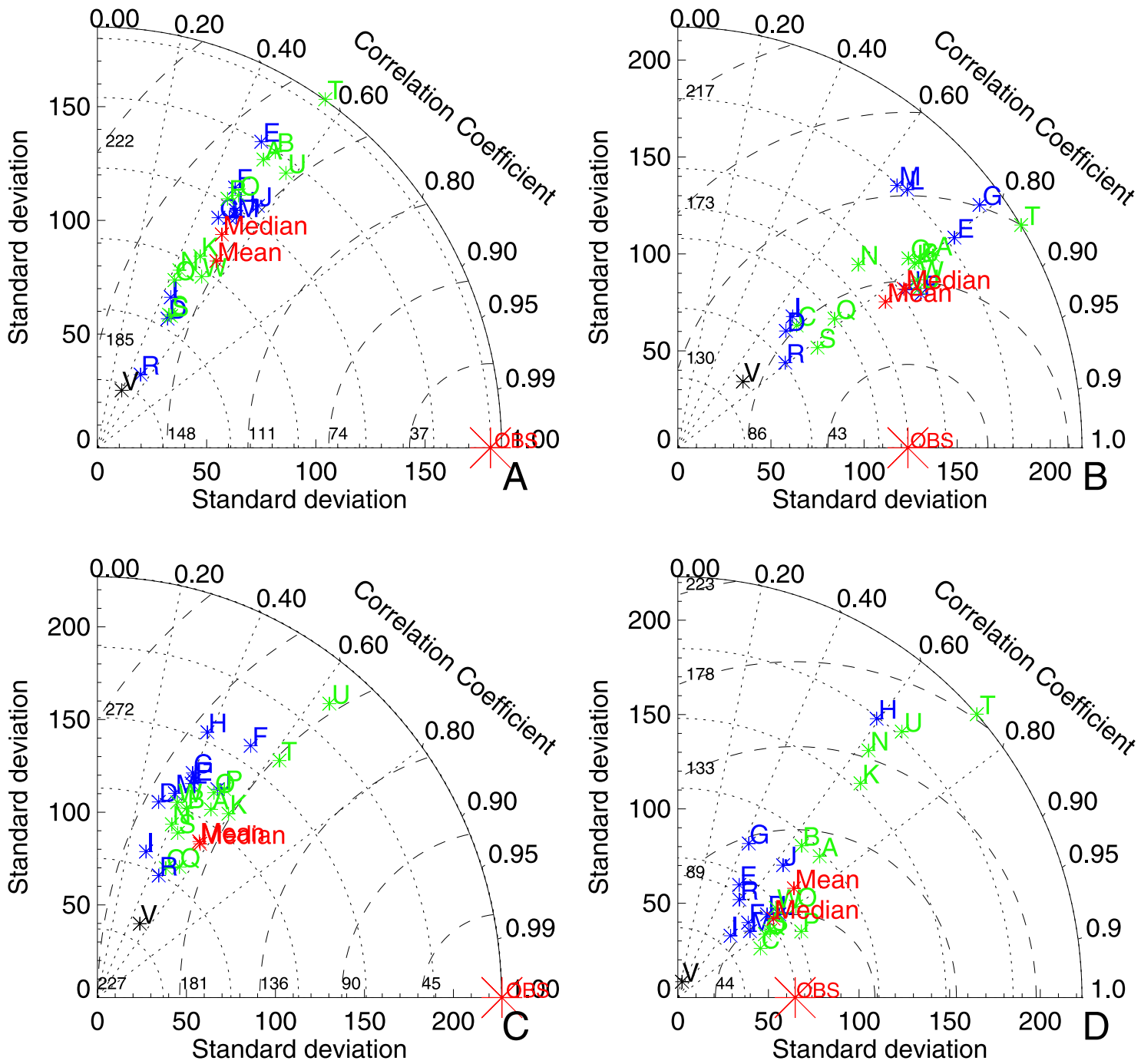

Figure 4. Taylor plots of correlation of modeled and measured $\mathrm{NO}_{3}\left(\mathrm{HNO}_{3}\right.$ and aerosol nitrate) wet deposition, and standard deviation of the model and measurements for four networks: (a) EMEP, Europe, (b) NADP, North America, (c) EAnet Asia, and (d) IDAF/DEBITS, Africa. Models indicated in green have resolution between $1^{\circ} \times 1^{\circ}$ and $3^{\circ} \times 4^{\circ}$; models in blue have resolutions around $4^{\circ} \times 5^{\circ}$. OBS (large red cross) indicates the mean of the observations. The horizontal and vertical axes give the standard deviation; the curved axis gives the correlation coefficient. The distance of a model to the observation is a measure of the root-mean-square error. Similar diagrams for $\mathrm{NH}_{\mathrm{x}}$ and $\mathrm{SO}_{4}$ deposition and model labels are found in the auxiliary material.

either deposited over land or exported to and deposited into the adjacent ocean. Surprisingly, the wet and total deposition over land shows a larger variability (standard deviation $\sigma=20 \%)$ than over sea $(\sigma=11 \%)$. Nevertheless, the total deposition taken from single models may differ by up to $30 \%$ from the mean model. Unfortunately, our study cannot resolve which individual model process (or resolution) caused the difference in calculated deposition, but it is not likely that resolution alone would cause these differences. For example the higher resolution models TM5 $\left(1^{\circ} \times 1^{\circ}\right.$ over Asia), and CHASER $\left(2.8^{\circ} \times 2.8^{\circ}\right)$ do not show obviously different deposition distributions over land and ocean than the mean model.

\subsubsection{Total Deposition}

[25] In Figures $7 \mathrm{a}-7 \mathrm{c}$ we present the mean, absolute and relative standard deviations of the present (S1-B2000) modeled $\mathrm{NO}_{\mathrm{y}}$ total deposition. The mean regions of high deposition are North America, western and eastern Europe, and East Asia. Despite large differences in model resolutions, chemistry parameterizations, and wet and dry removal processes, the variability $( \pm 1 \quad \sigma)$ of the model results in the source regions is relatively small compared to the absolute deposition $(20-30 \%)$. Larger relative variations $\left(100 \%\right.$ and more) in $\mathrm{NO}_{\mathrm{y}}$ deposition are found over the poles, oceans and in some tropical regions. Note, however, that the absolute deposition is small in these 

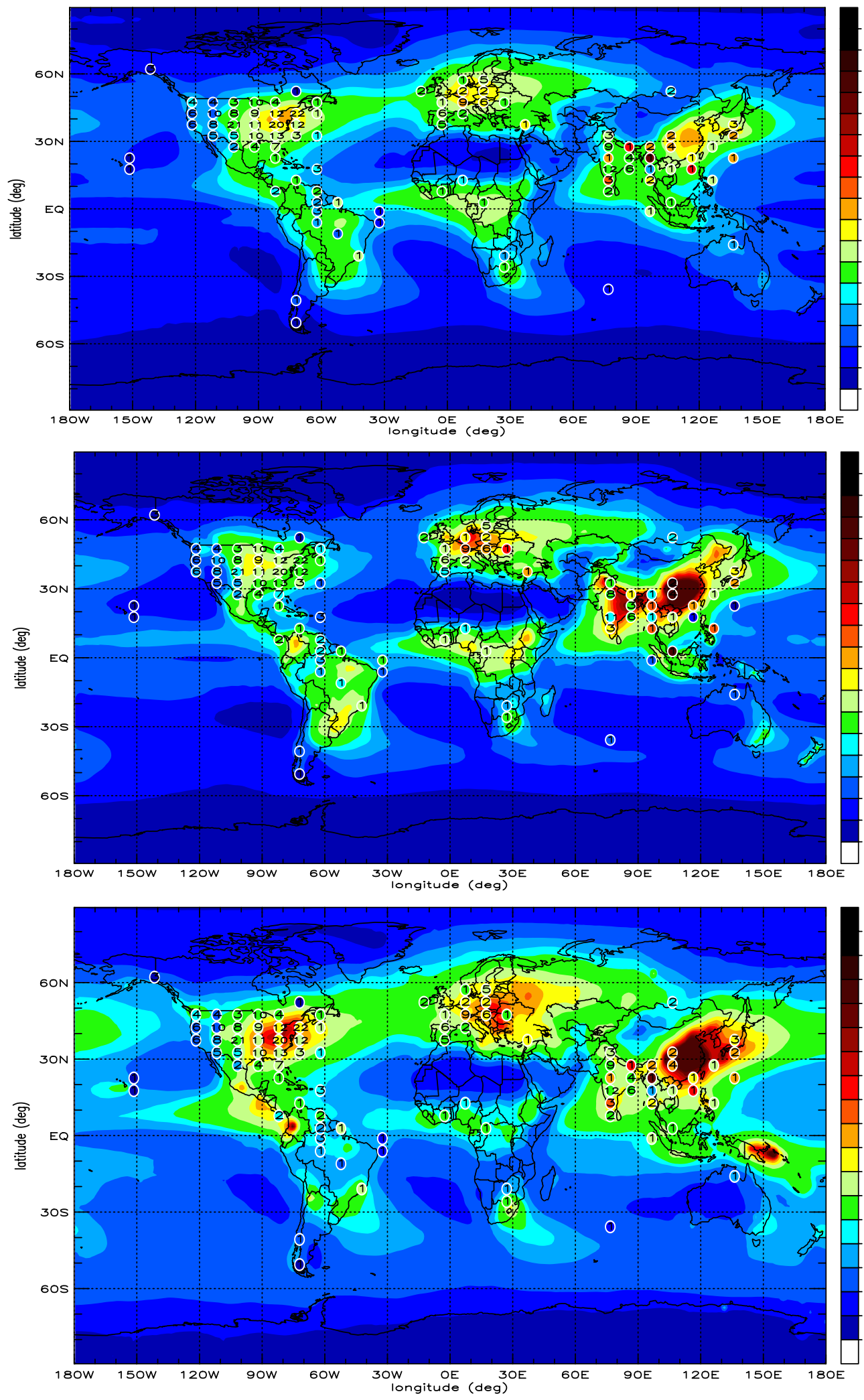

Figure 5. Annual (a) $\mathrm{NO}_{3}\left(\mathrm{HNO}_{3}\right.$ and aerosol nitrate), (b) $\mathrm{NH}_{\mathrm{x}}$ wet deposition, and (c) $\mathrm{SO}_{4}$ wet deposition for simulation S1 along with measurements grouped in $5^{\circ}$ latitude and $10^{\circ}$ longitude. The numbers within the circles indicate the number of stations in this latitude/longitude band. 
regions. In Figures $8 \mathrm{a}-8 \mathrm{c}$ we present the corresponding total deposition fields for $\mathrm{NH}_{\mathrm{x}}, \mathrm{SO}_{\mathrm{x}}$, and reactive Nitrogen (Nr) for S1-B2000. The largest total deposition of $\mathrm{NH}_{\mathrm{x}}$ is found over Europe, India and East Asia. $\mathrm{SO}_{\mathrm{x}}$ deposition dominates over North America, Europe and East Asia. Nr deposition is above the $1 \mathrm{gm}^{-2} \mathrm{yr}^{-1}$ level in extended parts of North America, Europe and Russia, Africa, South and East Asia. We further discuss the consequences for natural ecosystems in section 3.5.

\subsection{Future Deposition: Scenario Results}

[26] In Figures 9a-9c, 10a and 10b we present scenario results for the mean model of $\mathrm{NO}_{\mathrm{y}}$, and $\mathrm{Nr}$ for scenarios S2-CLE, S3-MFR and S4-A2 respectively; the corresponding figures for $\mathrm{NH}_{\mathrm{x}}$, and $\mathrm{SO}_{\mathrm{x}}$ are presented in auxiliary Figures fs07 and fs08. For CLE in Europe and parts of Russia the $\mathrm{NO}_{\mathrm{y}}$ deposition (Figure 9) decreases by $10-50 \%\left(100-250 \mathrm{mg}(\mathrm{N}) \mathrm{m}^{-2} \mathrm{yr}^{-1}\right)$. In North America, South and East Asia, $\mathrm{NO}_{\mathrm{y}}$ deposition further increases by $10-100 \%\left(100-500 \mathrm{mg}(\mathrm{N}) \mathrm{m}^{-2} \mathrm{yr}^{-1}\right)$. In contrast, $\mathrm{NO}_{\mathrm{y}} \mathrm{de}-$ position decreases by $30-70 \%\left(100-500 \mathrm{mg}(\mathrm{N}) \mathrm{m}^{-2} \mathrm{yr}^{-1}\right)$ for MFR over the continents. Note that the increase of $\mathrm{NO}_{\mathrm{y}}$ deposition over the Atlantic Ocean is related to ship emissions for which in all cases we assumed a CLE scenario (see section 2). Finally, $\mathrm{NO}_{\mathrm{y}}$ deposition increases by $50 \%$ in North America and Europe and up to a factor of 4 in South America, Africa and Asia, corresponding to an increase of 500-2000 $\mathrm{mg}(\mathrm{N}) \mathrm{m}^{-2} \mathrm{yr}^{-1}$ worldwide assuming the A2 scenario. The high increase over northern Siberia is due to inconsistencies in the assumed industrial activities between the SRES A2 scenario and the year 2000 S1 emissions; a similar situation may apply for the almost unchanged deposition over Australia. In both cases the absolute amounts of $\mathrm{NO}_{\mathrm{y}}$ deposition are rather small.

[27] $\mathrm{NH}_{\mathrm{x}}$ deposition in 2030 (auxiliary Figure fs07) decreases by $20-30 \%\left(100-250 \mathrm{mg}(\mathrm{N}) \mathrm{m}^{-2} \mathrm{yr}^{-1}\right)$ in Europe and Australia for CLE. In North and South America $\mathrm{NH}_{\mathrm{x}}$ deposition increases by $5-20 \%$, and in Africa and Asia by $50-100 \%$, corresponding to increases by up to $1000 \mathrm{mg}(\mathrm{N}) \mathrm{m}^{-2} \mathrm{yr}^{-1}$. Instead, the results for the A2 scenario indicate a small further increase by $10 \%$ of $\mathrm{NH}_{\mathrm{x}}$ deposition over Europe. The smaller increase of $\mathrm{NH}_{\mathrm{x}}$ deposition over India of A2 $(20 \%)$ compared to CLE $(50 \%)$ is caused by the smaller emissions of $\mathrm{NH}_{3}$ in $\mathrm{A} 2$ in that region than in CLE (B2). This counterintuitive result for India can be explained from the relatively small increase in population in the 2030 A2 scenario compared to present. In contrast, in the B2 scenario fewer people consume a more protein-rich diet, associated with the need for more arable land and more intensive agriculture. We further remark here that only two models provided $\mathrm{NH}_{\mathrm{x}}$ deposition for the S4-A2 scenario, making the averaged results less robust.

[28] $\mathrm{SO}_{\mathrm{x}}$ deposition in 2030 (auxiliary Figures fs08a-8c) decreases strongly in middle Europe (50\%), and moderately in the surrounding European countries, in North and Central America, Australia, and Japan $(20-50 \%)$ due to current legislation measures (S2-CLE). Also, northern Africa, in the outflow of Europe, profits from emission reductions in eastern Europe. In contrast, very strong increases of more than $50 \%\left(1000 \mathrm{mg}(\mathrm{S}) \mathrm{m}^{-2} \mathrm{yr}^{-1}\right)$ are foreseen for India and other parts of Asia and South America. In contrast, for the MFR scenario $\mathrm{SO}_{\mathrm{x}}$ deposition will strongly reduce by $50-80 \%$ in North America, Europe, and East Asia. Even the pessimistic SRES A2 scenarios assumed some $\mathrm{SO}_{2}$ emission controls in North America and Europe resulting in decreased deposition by $50 \%$, whereas $\mathrm{SO}_{\mathrm{x}}$ deposition in South America, Africa, South and East Asia would strongly increase by more than a factor of 2 .

[29] Finally we present in Figures 10a and 10b the change in $\mathrm{Nr}$ deposition considering CLE and A2. Except for Europe and Australia, for CLE nitrogen loads in 2030 would further increase by $20-100 \%$ (up to $2000 \mathrm{mg}(\mathrm{N}) \mathrm{m}^{-2} \mathrm{yr}^{-1}$ in South Asia). For A2 deposition on the continents would increase worldwide by $50-100 \%$, with the largest absolute increases of up to $2 \mathrm{~g}(\mathrm{~N}) \mathrm{m}^{-2} \mathrm{yr}^{-1}$ over East and South Asia.

\subsection{Role of Climate Change}

[30] How can climate change influence these deposition patterns? Climate feedbacks on deposition may occur through changes in meteorology (hydrological cycle, circulations patterns), atmospheric chemistry (oxidation capacity which is important for secondary aerosol formation), and emissions of nitrate, ammonium and sulfate precursors. In auxiliary Figures fs09a and fs09b we evaluate for five models the mean changes of deposition due to climate change by comparing $\mathrm{S} 5$ and $\mathrm{S} 2$.

[31] Both for $\mathrm{NO}_{\mathrm{y}}$ and $\mathrm{SO}_{\mathrm{x}}$ deposition the effects are relatively small compared to the predicted changes in the emissions, similar to what is reported by Lamarque et al. [2005]. The mean model (using results from the five models) indicates a slight increase of $0.6 \%$ in total $\mathrm{NO}_{\mathrm{y}}$ deposition due to climate change to be compared to an increase of $11 \%$ due to emission changes in the CLE scenario (S2-S1). Regionally, differences may amount to $20 \%$. All five models suggest increased precipitation, inducing an increase in wet and total $\mathrm{NO}_{\mathrm{y}}$ deposition, while the sign of the changes in global dry $\mathrm{NO}_{\mathrm{y}}$ deposition varies among the models. The largest effects are seen in the tropics where in most models climate change intensified the monsoon circulation. Another potential impact of climate change could be through changes in lightning emissions. Global lightning $\mathrm{NO}_{\mathrm{x}}$ emissions increase by $10 \%$ at most in the $\mathrm{S} 5$ simulations (only two models provided results), with most of the changes occurring in the tropics. We mention here also the possibility of a change of $\mathrm{NO}_{\mathrm{y}}$ influx from the stratosphere into the troposphere; in our study we did not quantify this influx, but we estimate the effect to be small. However, it is unclear to what extent this increase translates into changes in $\mathrm{NO}_{\mathrm{y}}$ deposition.

\subsection{Deposition on Continents, Coastal Shelves, and Ecosystems}

[32] Auxiliary Tables ts 08 , ts 09 , and ts 10 present the mean, median and the standard deviation of the calculated deposition using the IMAGE2 world region definition (see auxiliary Figure fs01) for the year 2000. On the basis of these tables we compare in auxiliary Figure fs06 the 

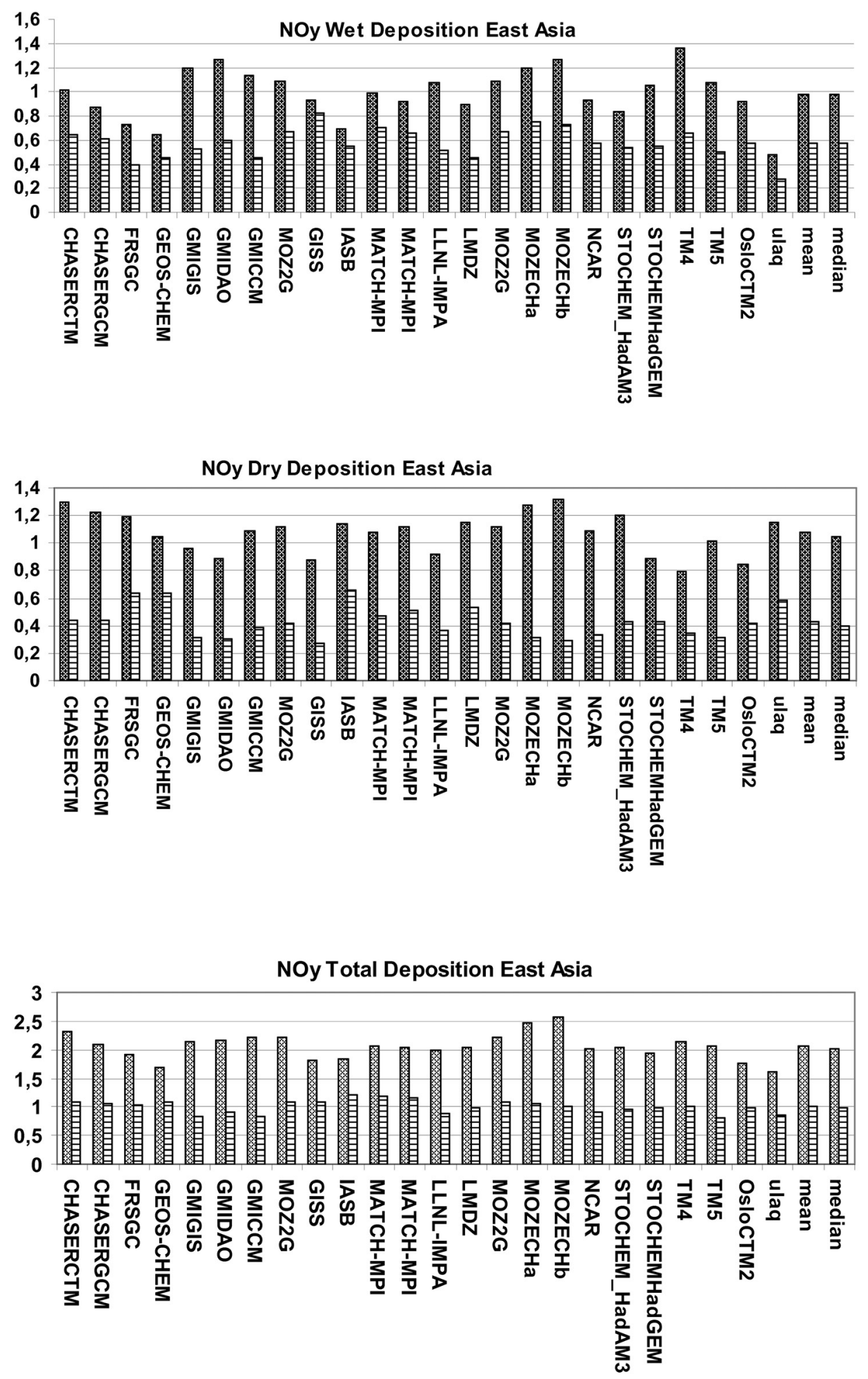

Figure 6. Analysis of the annual $\mathrm{NO}_{\mathrm{y}}$ deposition budgets $\left(\mathrm{Tg}(\mathrm{N}) \mathrm{yr}^{-1}\right)$ for simulation $\mathrm{S} 1$ over East Asia $\left(20^{\circ} \mathrm{N}-45^{\circ} \mathrm{N} ; 110^{\circ} \mathrm{E}-130^{\circ} \mathrm{E}\right)$ analyzing the deposition over land and sea for individual models (a) $\mathrm{NO}_{\mathrm{y}}$ wet deposition, (b) $\mathrm{NO}_{\mathrm{y}}$ dry deposition, and (c) $\mathrm{NO}_{\mathrm{y}}$ total deposition. Left bars denote land; right bars denote ocean. 

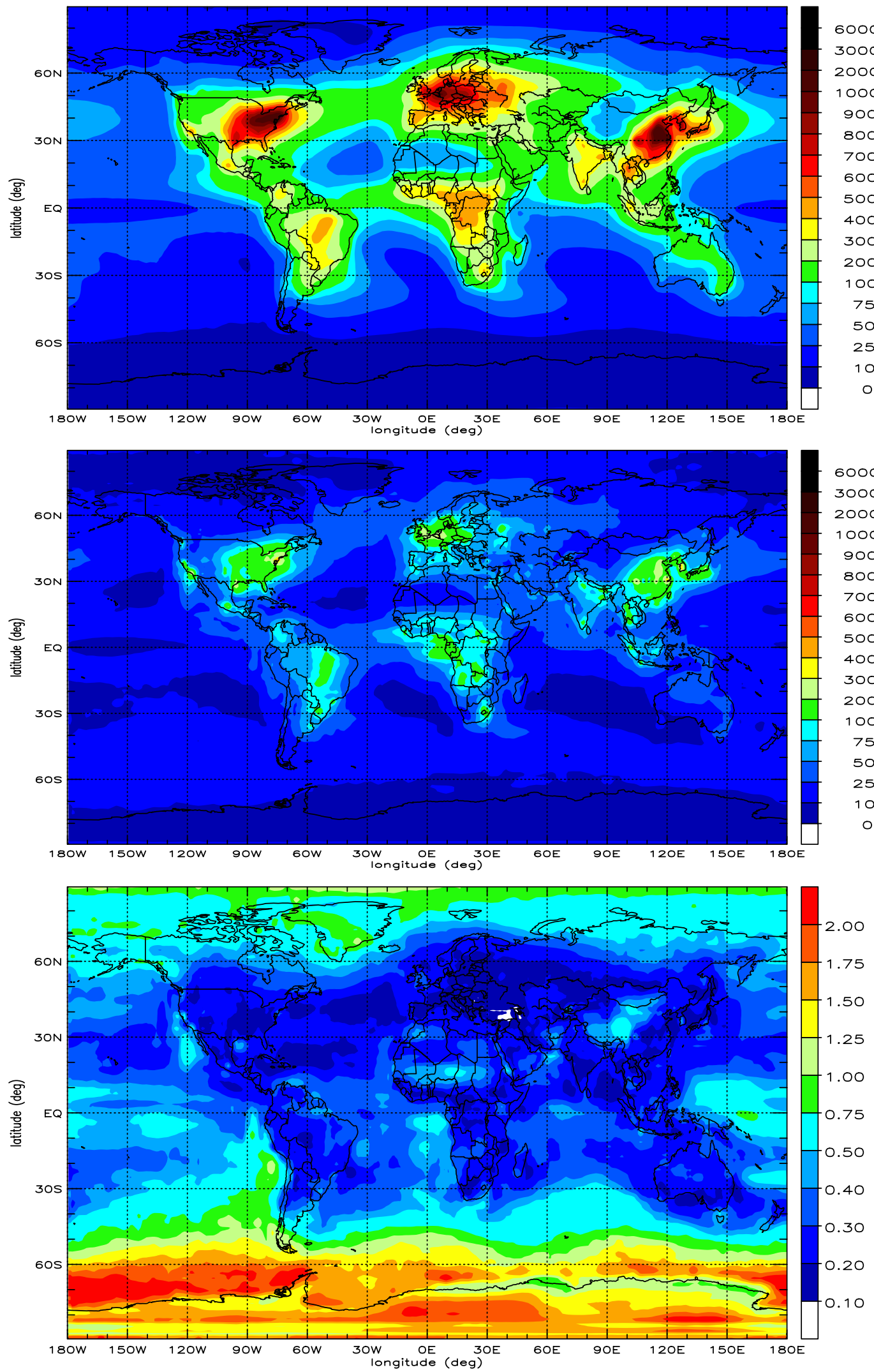

Figure 7. (a) Total annual deposition of $\mathrm{NO}_{\mathrm{y}}\left(\mathrm{mg}(\mathrm{N}) \mathrm{m}^{-2} \mathrm{yr}^{-1}\right)$ for the mean model; (b) absolute standard deviation $\left(\mathrm{mg}(\mathrm{N}) \mathrm{m}^{-2} \mathrm{yr}^{-1}\right)$ of the $\mathrm{NO}_{\mathrm{y}}$ deposition, and (c) relative standard deviation of the mean $\mathrm{NO}_{\mathrm{y}}$ deposition for simulation $\mathrm{S} 1$. 

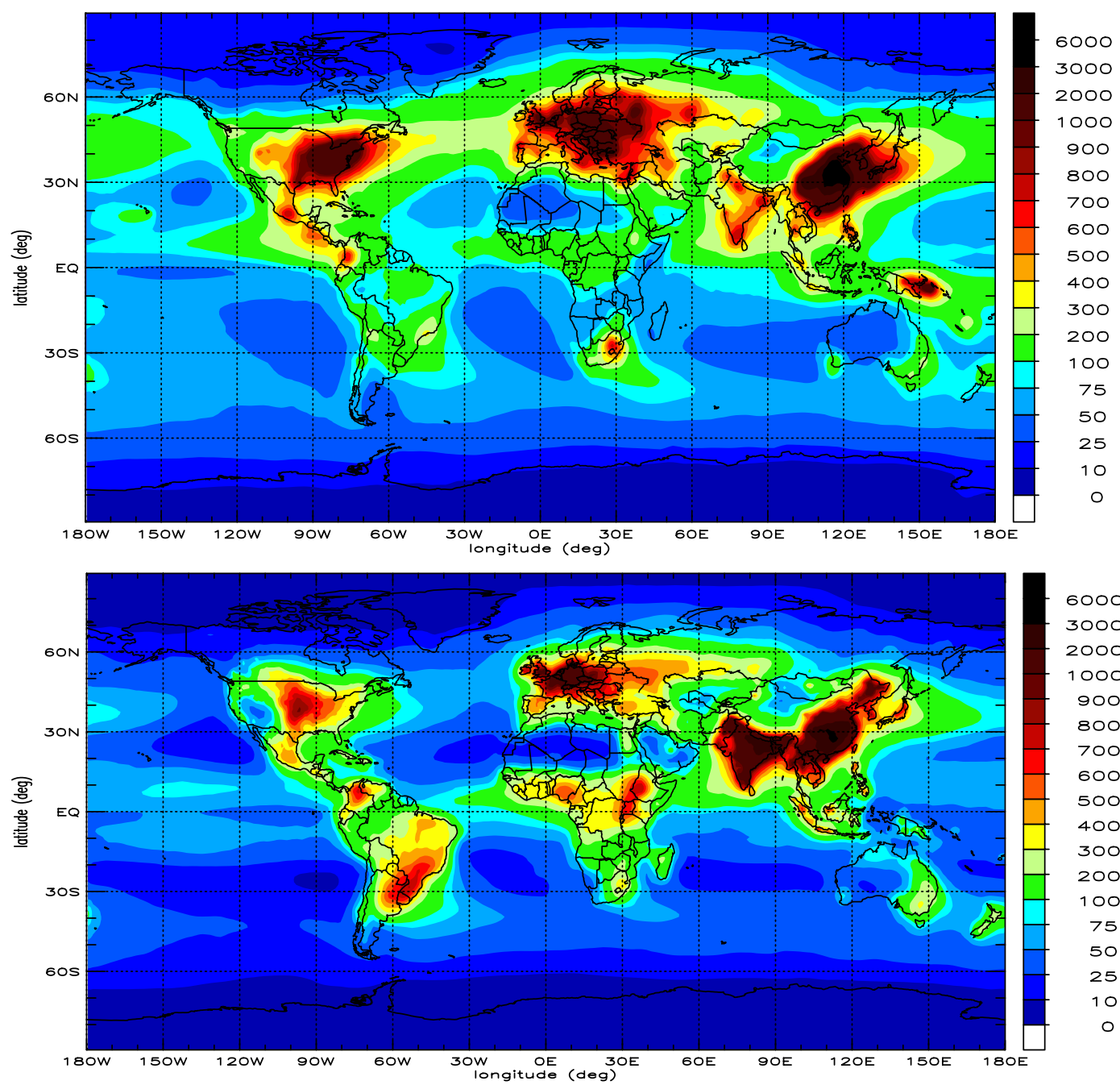

6000

3000

2000

1000

900

800

700

600

500

400

300

200

100

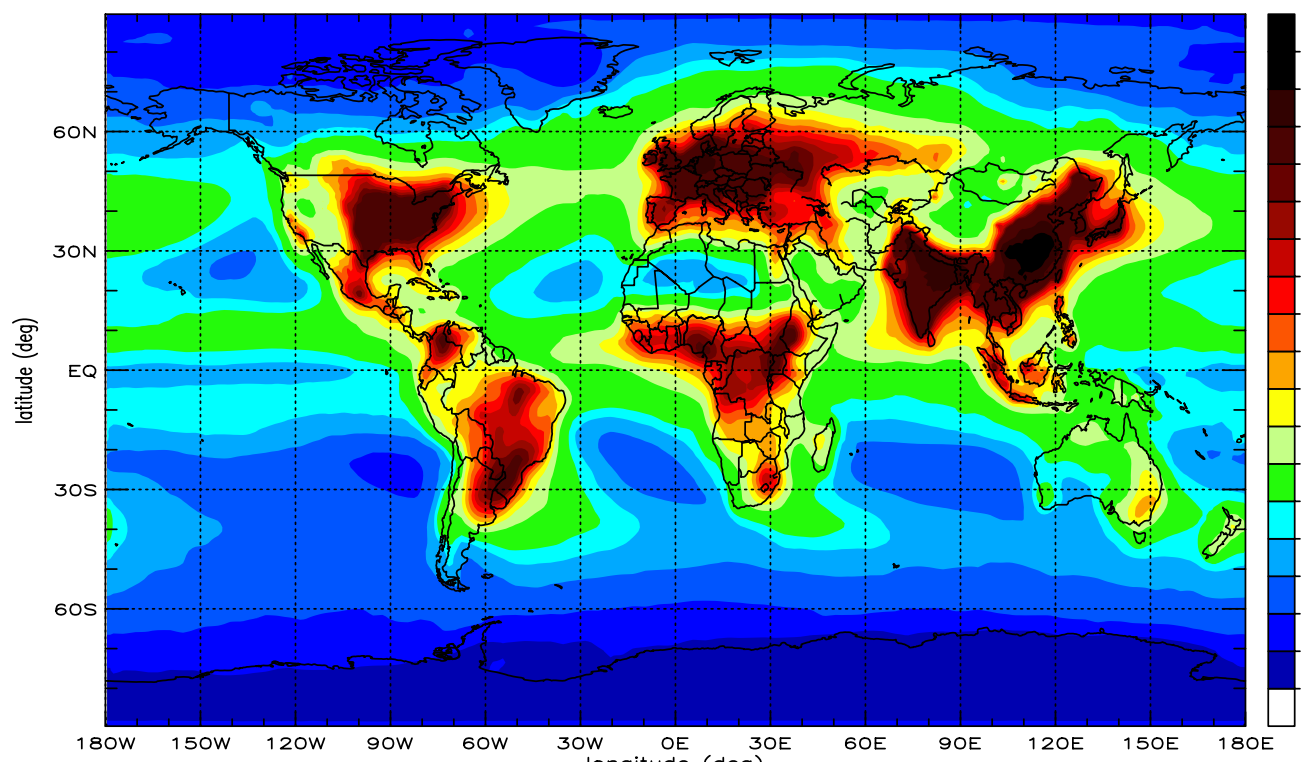

Figure 8. (a) Total deposition $\left(\mathrm{mg}(\mathrm{S}) \mathrm{m}^{-2} \mathrm{yr}^{-1}\right)$ of $\mathrm{SO}_{\mathrm{x}}$, (b) total deposition $\left(\mathrm{mg}(\mathrm{N}) \mathrm{m}^{-2} \mathrm{yr}^{-1}\right)$ of $\mathrm{NH}_{\mathrm{x}}$, and (c) total deposition $\left(\mathrm{mg}(\mathrm{N}) \mathrm{m}^{-2} \mathrm{yr}^{-1}\right)$ of $\mathrm{Nr}$ for year 2000. 

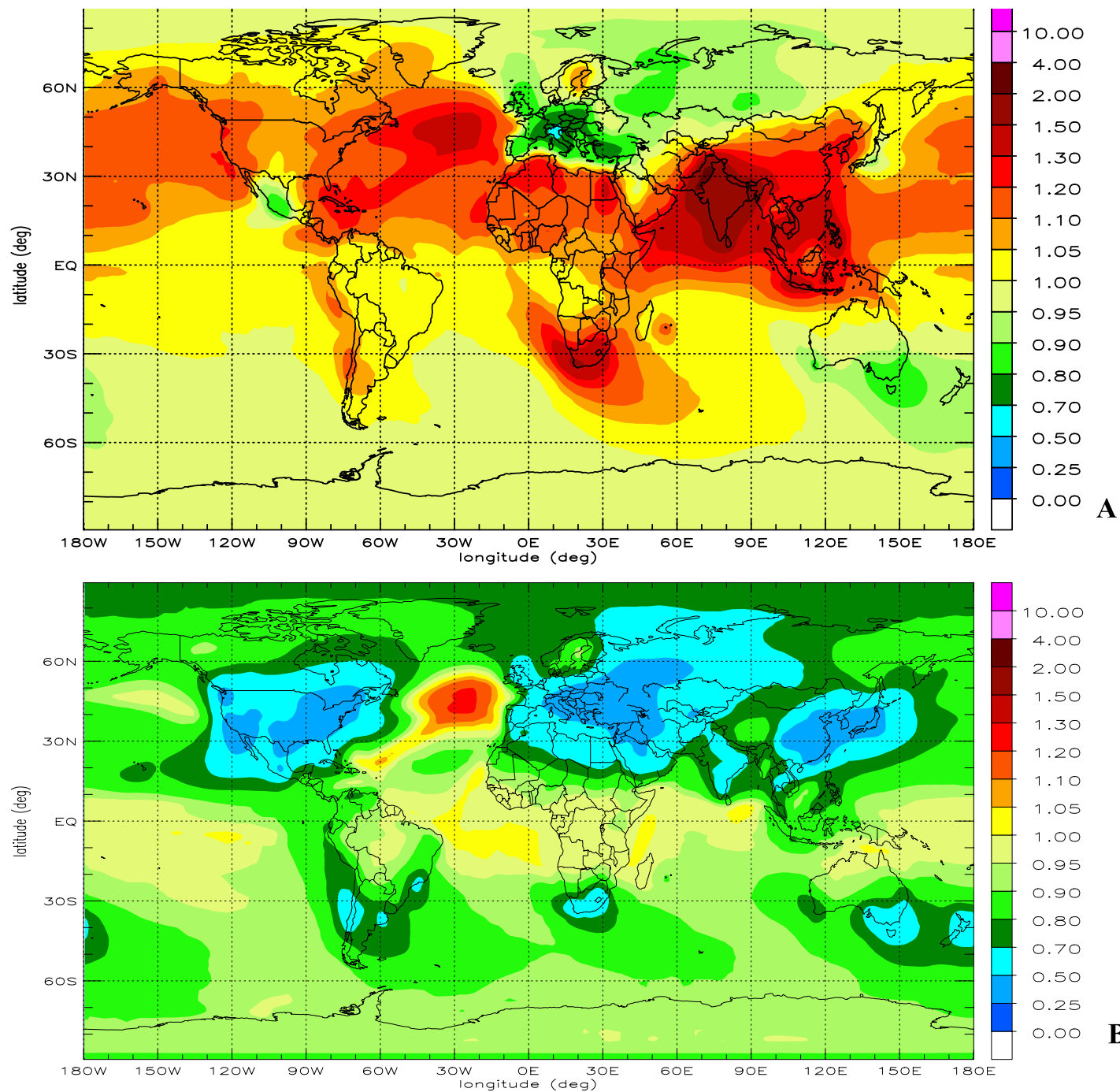

\subsection{0}

4.00

2.00

1.50

1.30

1.20

1.10

1.05

1.00

0.95

0.90

0.80

0.70

0.50

0.25

$0.00 \quad$ B

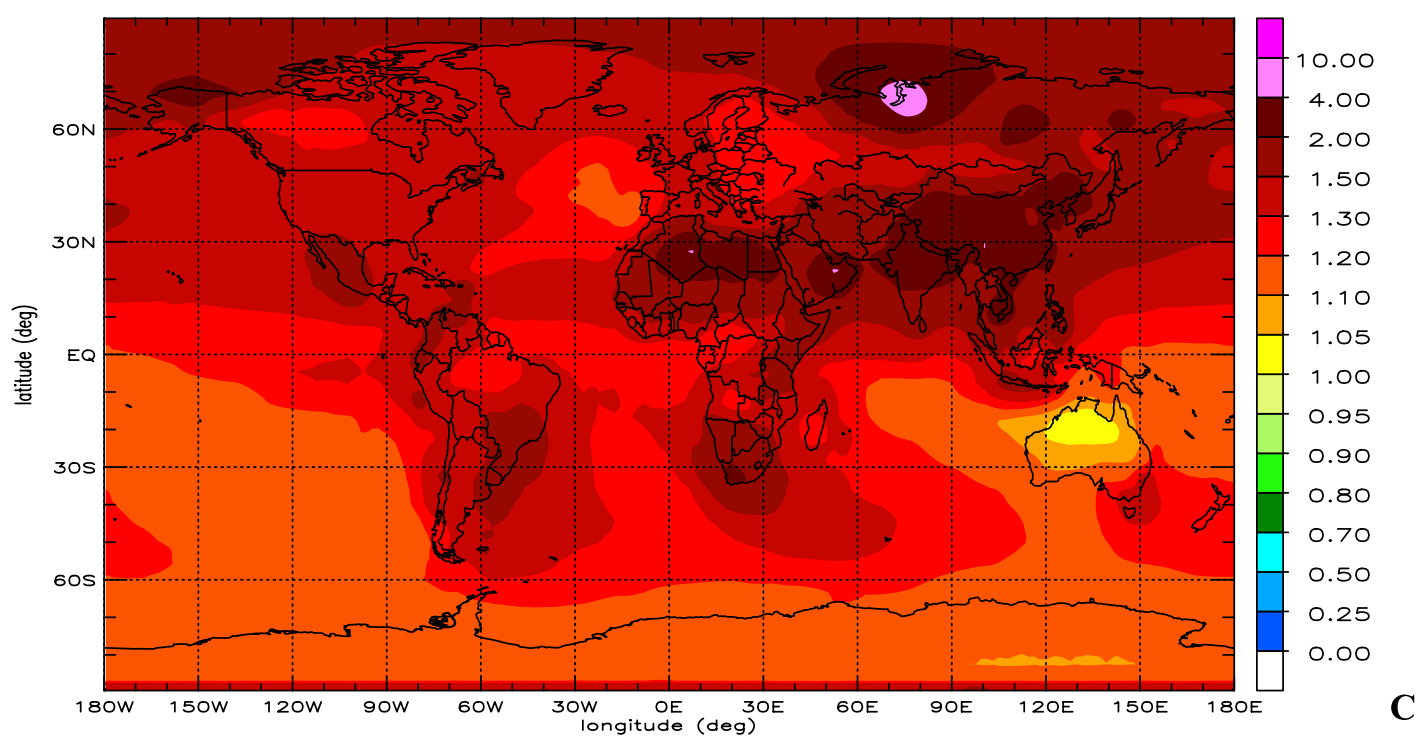

Figure 9. a: Ratio of total deposition of $\mathrm{NO}_{\mathrm{y}}$ of the mean model for scenario (a) S2 CLE compared to base simulation S1 (B2000), (b) S3/MFR compared to S1, and (c) S4/A2 compared to S1. 

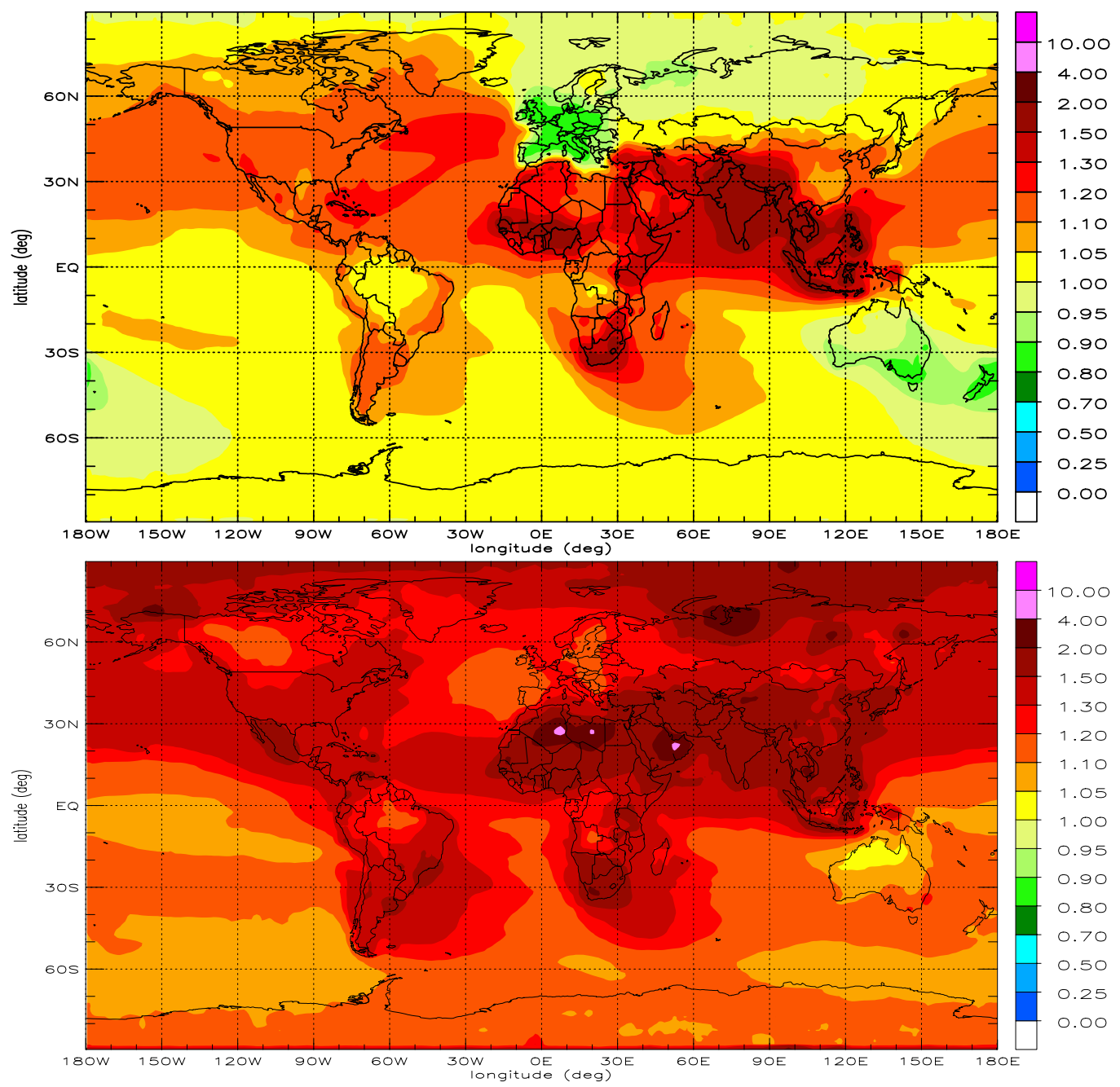

Figure 10. a: Ratio of total deposition of reactive $\mathrm{Nr}$ of the mean model for scenario (a) S2/CLE compared to base simulation S1 (B2000) and (b) S4/A2 compared to S1.

corresponding anthropogenic emission and deposition fluxes to evaluate regional balance of nitrogen and sulfur import and export. The regions with largest average $\mathrm{NO}_{\mathrm{y}}$ deposition are the United States, western (OECD) and eastern Europe and Japan. These regions are also large net exporters of $\mathrm{NO}_{\mathrm{y}}$. Oceans receive $22.6 \mathrm{Tg}(\mathrm{N}) \mathrm{yr}^{-1}$ of which the coastal shelves $3.7 \mathrm{Tg}(\mathrm{N}) \mathrm{yr}^{-1}$, representing $43 \%$ and $7.5 \%$ of all $\mathrm{NO}_{\mathrm{x}}$ emissions. This fraction of $\mathrm{NO}_{\mathrm{y}}$ deposition over the oceans is substantially different from the previous estimate by Lamarque et al. [2005] amounting to $30 \%$. The difference is due to a different set of models in the latter study, and the fact that their model results were gridded to T30 resolution and associated with a similar land-sea mask. In contrast the calculations in this paper were all performed on $1^{\circ} \times 1^{\circ}$ resolution. For $\mathrm{NH}_{\mathrm{x}}$ the regions exposed to deposition larger than $300 \mathrm{mg}(\mathrm{N}) \mathrm{m}^{-2} \mathrm{yr}^{-1}$ are South America, OECD and east Europe, and all regions in Asia. Oceanic receive $23.5 \mathrm{Tg}(\mathrm{N}) / \mathrm{yr}$ of which coastal regions $4.0 \mathrm{Tg}(\mathrm{N}) / \mathrm{yr}$, corresponding to $37 \%$ and $6 \%$ of all emissions, respectively. Note that oceans are thought to be a $\mathrm{NH}_{3}$ source of
4-8 $\operatorname{Tg}(\mathrm{N}) \mathrm{yr}^{-1}$ [Bouwman et al., 1997; Galloway et al., 2004]; a small fraction of these emissions are transported to the continents. Large net exporters of $\mathrm{NH}_{\mathrm{x}}$ are Europe and Asia. Regions with largest $\mathrm{SO}_{\mathrm{x}}$ deposition are the United States, Europe, East Asia and Japan. The largest exporters of $\mathrm{SO}_{\mathrm{x}}$ are the USA, eastern Europe, Middle East, and South and East Asia. Interestingly, in contrast to $\mathrm{NO}_{\mathrm{y}}$ and $\mathrm{NH}_{\mathrm{x}}$, Japan receives almost equal amounts of $\mathrm{SO}_{\mathrm{x}}$ compared to the emitted amounts; this is due to the vicinity of sulfur emitting volcanoes, as well as transport of sulfate from China.

[33] We use the 23 classes of the global land cover data set GLC 2000 (http://www-gvm.jrc.it/glc2000), which used an underlying resolution of $1 \mathrm{~km} \times 1 \mathrm{~km}$, to classify vegetation on a $1^{\circ} \times 1^{\circ}$ resolution in four groups: natural (nonagricultural) vegetation, agricultural and urbanized land use types, bare soils and deserts, and water bodies (including oceans). This grid matches the resolution of the interpolated model results.

[34] Figures 11a-11c presents an analysis of the fraction of the continental $\mathrm{NO}_{\mathrm{y}}, \mathrm{NH}_{\mathrm{x}}$ and $\mathrm{SO}_{\mathrm{x}}$ deposition on these 
Table 2. $\mathrm{NO}_{\mathrm{y}}, \mathrm{NH}_{\mathrm{x}}$ and $\mathrm{SO}_{\mathrm{x}}$ Deposition for the Four Scenarios per Region ${ }^{\mathrm{a}}$

\begin{tabular}{|c|c|c|c|c|c|c|c|c|c|c|c|}
\hline Scenario Region & $\mathrm{S} 1 \mathrm{NO}_{\mathrm{y}}$ & $\mathrm{S} 2 \mathrm{NO}_{\mathrm{y}}$ & $\mathrm{S} 3 \mathrm{NO}_{\mathrm{y}}$ & $\mathrm{S} 4 \mathrm{NO}_{\mathrm{y}}$ & $\mathrm{S} 1 \mathrm{NH}_{\mathrm{x}}$ & $\mathrm{S} 2 \mathrm{NH}_{\mathrm{x}}$ & $\mathrm{S} 4 \mathrm{NH}_{\mathrm{x}}$ & $\mathrm{S} 1 \mathrm{SO}_{\mathrm{x}}$ & $\mathrm{S} 2 \mathrm{SO}_{\mathrm{x}}$ & $\mathrm{S} 3 \mathrm{SO}_{\mathrm{x}}$ & $\mathrm{S} 4 \mathrm{SO}_{\mathrm{x}}$ \\
\hline Canada & 83.8 & 93.0 & $\downarrow 48.8$ & $\uparrow 117.2$ & 79.6 & 86.9 & 98.1 & 119.6 & 115.3 & $\downarrow 43.0$ & $\downarrow 87.7$ \\
\hline USA & 386.5 & 425.2 & $\downarrow 177.5$ & $\uparrow 542.4$ & 297.0 & 321.0 & $\uparrow 375.9$ & 557.4 & 521.8 & $\downarrow 119.5$ & 405.9 \\
\hline C. America & 219.9 & 218.0 & $\downarrow 135.5$ & $\uparrow 353.2$ & 248.0 & 325.6 & $\uparrow 366.9$ & 335.3 & $\downarrow 230.5$ & $\downarrow 138.6$ & $\downarrow 596.4$ \\
\hline S. America & 218.9 & 223.2 & 194.7 & $\uparrow 311.8$ & 300.9 & $\uparrow 342.5$ & $\uparrow 400.7$ & 139.0 & 152.7 & 113.7 & $\uparrow 301.9$ \\
\hline N. Africa & 113.2 & 134.4 & $\downarrow 74.3$ & $\uparrow 230.1$ & 74.1 & 89.9 & $\uparrow 98.6$ & 130.5 & $\downarrow 118.5$ & $\downarrow 65.0$ & $\uparrow 246.5$ \\
\hline W. Africa & 261.0 & 281.2 & 249.2 & $\uparrow 368.7$ & 239.9 & 369.0 & $\uparrow 373.3$ & 92.4 & 94.0 & $\downarrow 62.6$ & $\uparrow 229.1$ \\
\hline E. Africa & 169.0 & 188.5 & 157.0 & $\uparrow 262.5$ & 289.0 & $\uparrow 413.0$ & $\uparrow 408.8$ & 99.9 & 105.8 & $\downarrow 60.9$ & $\uparrow 217.0$ \\
\hline S. Africa & 236.6 & 266.1 & 216.7 & $\uparrow 363.8$ & 169.6 & $\uparrow 240.0$ & $\uparrow 226.5$ & 131.5 & 136.0 & $\downarrow 55.7$ & $\uparrow 476.7$ \\
\hline OECD Europe & 465.7 & 392.7 & $\downarrow 280.1$ & $\uparrow 619.8$ & 537.1 & 462.2 & 540.2 & 580.1 & $\downarrow 402.9$ & $\downarrow 272.3$ & 435.5 \\
\hline E. Europe & 618.5 & 485.0 & $\downarrow 278.8$ & 761.4 & 705.3 & 659.7 & 712.0 & 1358.8 & $\downarrow 643.9$ & $\downarrow 290.7$ & 1383.4 \\
\hline Former USSR & 146.4 & 137.8 & $\downarrow 79.9$ & $\uparrow 216.7$ & 164.0 & 176.4 & 197.9 & 272.2 & $\downarrow 169.9$ & $\downarrow 67.8$ & 304.1 \\
\hline Middle East & 192.7 & 193.2 & $\downarrow 100.3$ & $\uparrow 355.6$ & 160.5 & $\uparrow 260.0$ & $\uparrow 294.9$ & 311.0 & $\downarrow 185.0$ & $\downarrow 68.8$ & $\uparrow 577.9$ \\
\hline South Asia & 262.5 & $\uparrow 455.6$ & $\downarrow 180.2$ & $\uparrow 569.3$ & 1108.3 & $\uparrow 1855.6$ & $\uparrow 1474.7$ & 411.9 & $\uparrow 1045.7$ & $\downarrow 182.0$ & $\uparrow 1502.7$ \\
\hline East Asia & 300.1 & 370.9 & $\downarrow 151.2$ & $\uparrow 666.4$ & 741.8 & 795.9 & 869.9 & 858.0 & 910.9 & $\downarrow 214.5$ & $\uparrow 1344.0$ \\
\hline S. East Asia & 254.8 & $\uparrow 326.6$ & $\downarrow 193.2$ & $\uparrow 428.8$ & 478.3 & $\uparrow 819.6$ & $\uparrow 761.8$ & 301.8 & $\uparrow 484.3$ & $\downarrow 174.5$ & $\uparrow 877.2$ \\
\hline Oceania & 87.5 & 85.2 & 76.5 & 97.7 & 92.3 & 91.0 & 98.5 & 99.5 & 86.0 & $\downarrow 68.8$ & 102.4 \\
\hline Japan & 433.8 & 430.8 & $\downarrow 184.0$ & $\uparrow 712.4$ & 434.5 & 481.5 & $\uparrow 569.5$ & 794.7 & 776.2 & $\downarrow 390.4$ & $\uparrow 1577.3$ \\
\hline Greenland & 17.7 & 18.9 & 15.6 & $\uparrow 25.7$ & 9.6 & 11.8 & $\uparrow 15.8$ & 24.8 & 23.2 & $\downarrow 15.7$ & 24.1 \\
\hline Ocean & 60.7 & 68.0 & 48.1 & $\uparrow 86.6$ & 62.9 & 75.3 & $\uparrow 84.1$ & 112.1 & 120.9 & $\downarrow 82.0$ & $\uparrow 165.0$ \\
\hline$N H$ & 150.4 & 169.0 & 101.0 & $\uparrow 239.1$ & 188.9 & 240.8 & $\uparrow 252.2$ & 248.0 & 256.1 & $\downarrow 114.1$ & $\uparrow 374.8$ \\
\hline SH & 53.9 & 56.7 & 48.1 & $\uparrow 71.5$ & 63.9 & 72.6 & $\uparrow 80.1$ & 71.9 & 75.1 & 61.9 & $\uparrow 115.0$ \\
\hline World & 102.2 & 112.9 & $\downarrow 74.5$ & $\uparrow 155.3$ & 126.4 & 156.7 & $\uparrow 166.2$ & 160.0 & 165.6 & $\downarrow 88.0$ & $\uparrow 244.9$ \\
\hline
\end{tabular}

four surface types (see Table 2). In most regions the largest fraction $(50-70 \%)$ of $\mathrm{NO}_{\mathrm{y}}, \mathrm{NH}_{\mathrm{x}}$ and $\mathrm{SO}_{\mathrm{x}}$ deposition falls on natural vegetation. Exceptions are northern Africa and the Middle East, where deserts receive most deposition, and eastern Europe where most deposition is on agricultural regions. Worldwide in the year 2000, about $42 \%$ of all $\mathrm{NO}_{\mathrm{y}}$ is deposited on natural vegetation, $12 \%$ on agricultural and urbanized regions, a few percent on deserts (consistent with auxiliary Tables ts08-ts10), and the remainder on water bodies. Rather similar numbers are found for $\mathrm{NH}_{\mathrm{x}}: 40 \%$, $18 \%$ and $38 \%$. In contrast, a large fraction of sulfate deposition takes place over the ocean (53\%) This is related to the relatively large contribution of natural DMS and volcanic emissions to the sulfur budget; $32 \%$ and $12 \%$ of the $\mathrm{SO}_{\mathrm{x}}$ deposition is on natural vegetation and urban/ agricultural land, respectively.

[35] In Figure 12a we give the fraction of the natural vegetation that receives nitrogen deposition above a threshold level of $1 \mathrm{~g}(\mathrm{~N}) \mathrm{m}^{-2} \mathrm{yr}^{-1}$. In sensitive ecosystems above this threshold changes in ecosystem functioning may occur [Bobbink et al., 1998; Bouwman et al., 2002b], a concept known as "critical nitrogen load." According to our calculations $10 \%$ of the world's natural vegetation is currently exposed to nitrogen deposition above this critical nitrogen load, a number which may further increase to $15 \%$ assuming CLE, and $20 \%$ for A2. For MFR, for which we did not have a separate $\mathrm{NH}_{3}$ emission scenario, the decreased $\mathrm{NO}_{y}$ deposition is compensated by increased $\mathrm{NH}_{\mathrm{x}}$ deposition. More than $20 \%$ of the natural vegetation in the United States, Europe, and Asia (including Japan) receives atmospheric nitrogen deposition in excess of $1 \mathrm{~g}(\mathrm{~N}) \mathrm{m}^{-2} \mathrm{yr}^{-1}$. Whereas for S2-CLE this exceedance slightly decreases in Europe, it further increases in Asia. For the CLE scenario parts of Africa will become exposed to excess nitrogen loads. For S4-A2 nitrogen deposition are in excess of $1 \mathrm{~g}(\mathrm{~N}) \mathrm{m}^{-2} \mathrm{yr}^{-1}$ for large fractions of almost all world regions corresponding to a worldwide increase of $150 \%$.
We note that in the previous analysis we assumed that future land use would be similar to that in the year 2000 .

[36] We finish with a qualitative assessment of the importance of a multimodel analysis for nitrogen deposition. Phoenix et al. [2006] use the ecosystem biodiversity hotspot map of Myers et al. [2000] to calculate the threat of $\mathrm{N}$ deposition to biodiversity at the global scale; they find that currently 8 of 25 hotspots receive nitrogen deposition above the $1 \mathrm{gm}^{-2} \mathrm{yr}^{-1}$ threshold. Their analysis was based on the results of a single model (TM3). Since these hotspots are often located at a distance of 500-1000 km from emission regions, it is interesting to analyze how different models predict the long-range transport and deposition of nitrogen components to these sensitive regions. We choose from these hotspots (e.g., Brazilian Atlantic Forest) a single $1^{\circ} \times 1^{\circ}$ model grid (e.g., $23^{\circ} \mathrm{S}-135^{\circ} \mathrm{W}$ ) and determined the minimum, mean, and maximum of $\mathrm{Nr}$ deposition. Figure 12b shows that at these hotspots the model spread of $\mathrm{Nr}$ deposition is of the order of $50 \%$. At some locations the spread of the ensemble model calculation is larger than the predicted increase for the future scenarios; this is important in the context of the threshold based estimates of ecosystem vulnerability.

\section{Discussion and Conclusions}

[37] We compute current and future deposition of reactive nitrogen $\left(\mathrm{NO}_{\mathrm{y}}\right.$ and $\left.\mathrm{NH}_{\mathrm{x}}\right)$ and sulfate to land and ocean surfaces using a 23-member ensemble of models. The models are driven by three different emission scenarios for the year 2030. The first (CLE) reflects worldwide currently decided air quality legislation, while the second (MFR) represents an optimistic case assuming that all technology currently available would be used to achieve all possible emissions reductions. However, it does not consider progressive energy use scenarios, or for instance a substantial fuel shift toward hydrogen, which may have similar (or even better) effects on reducing emissions than 


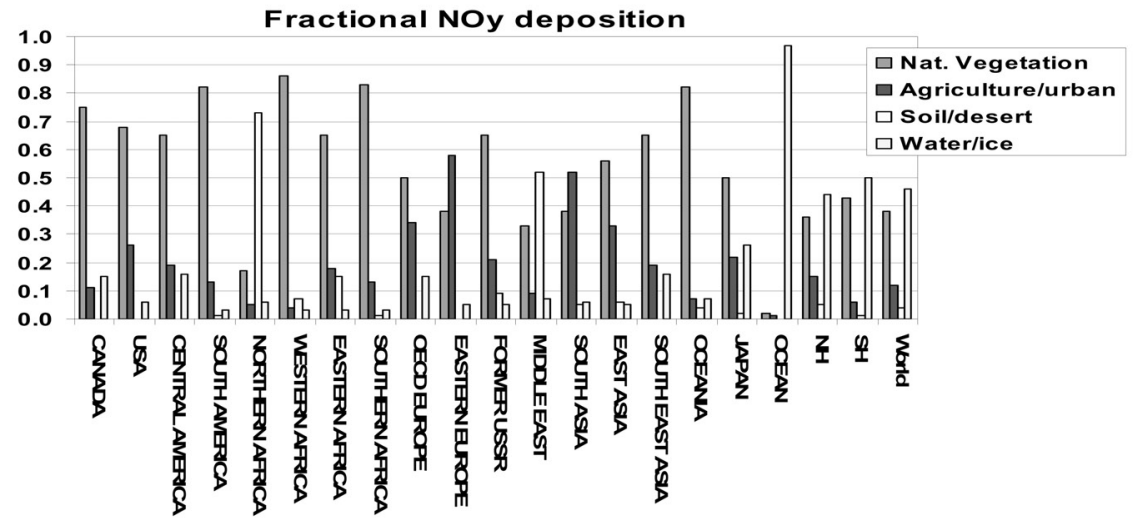

A

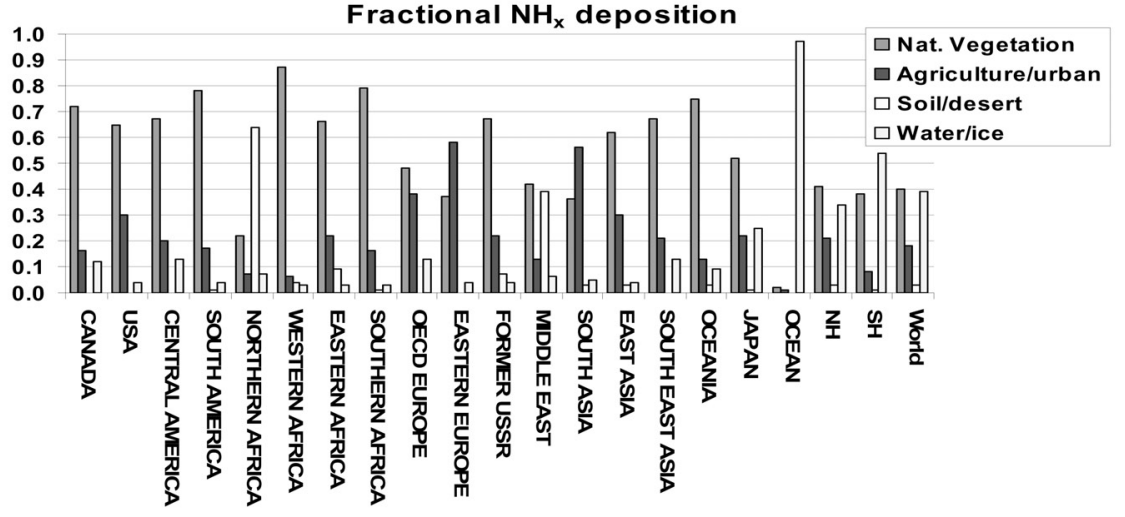

B

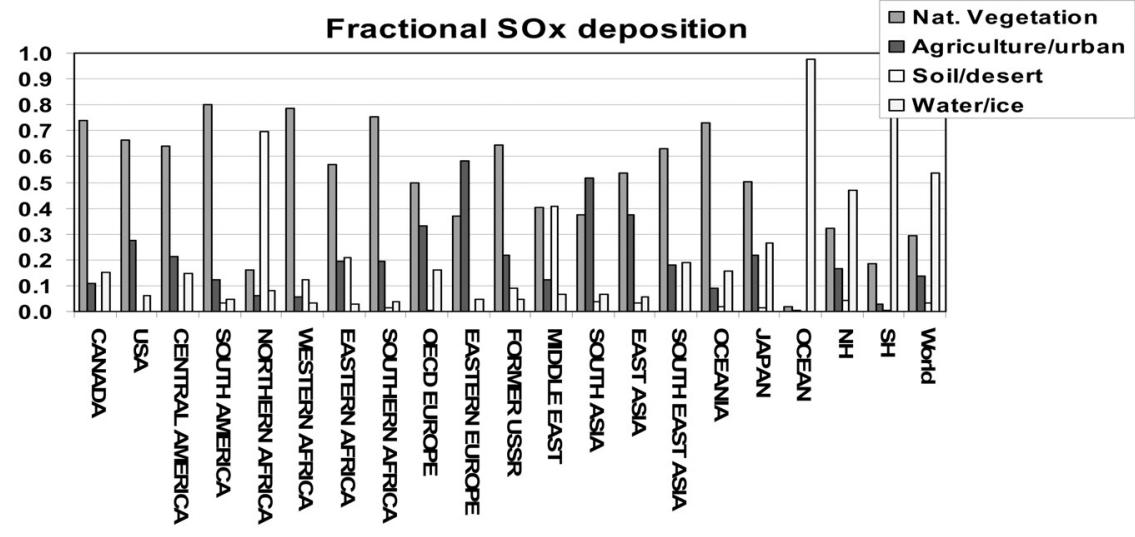

C

Figure 11. Fraction of deposition on natural vegetation, agricultural/urban surfaces, soils desert, and water for the year 2000 for (a) $\mathrm{NO}_{\mathrm{y}}$, (b) $\mathrm{NH}_{\mathrm{x}}$, or (c) $\mathrm{SO}_{\mathrm{x}}$.

MFR. We contrast these scenarios with the pessimistic IPCC SRES A2 scenario. An extensive discussion on the use of these scenarios was given by Dentener et al. [2005]. The actual development of emissions in the next decades will critically depend on whether and to what extent emission regulations will be implemented.

[38] This study also included an evaluation of the role of reduced nitrogen $\mathrm{NH}_{3}$ emissions. Much less is known about current and future developments of worldwide $\mathrm{NH}_{3}$ emissions [Bouwman et al., 2002a, 1997; Dentener and Crutzen,
1994]. Often emission factors in developing countries are derived by simple adaptation or scaling of factors from Europe and North America. Future scenarios may profit from better knowledge of emission factors in developing countries, and of the anticipated development of the global food production system. Linking future emissions to FAO projections regarding anticipated increase in population and food demand would be desirable. In this study we did not consider a separate MFR scenario for $\mathrm{NH}_{3}$, since a serious evaluation of the potential to reduce $\mathrm{NH}_{3}$ emissions was 
Fraction $\mathrm{Nr}$ deposition in excess of $1 \mathrm{~g} / \mathrm{m} 2 / y e$ ar on natural ecosystems

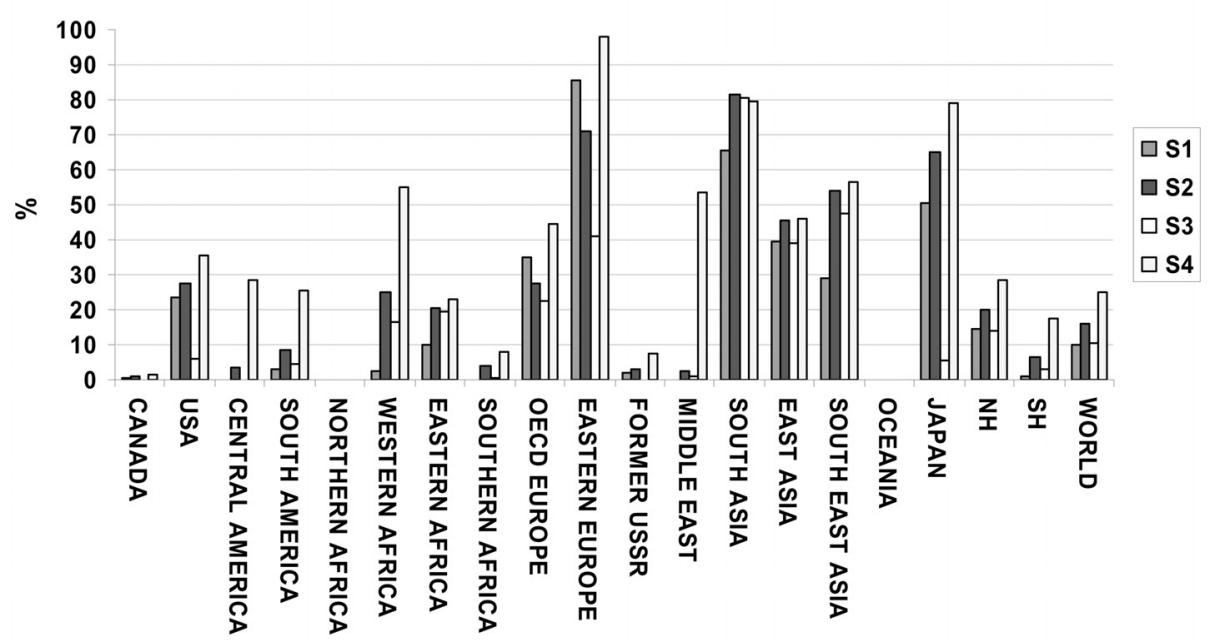

A

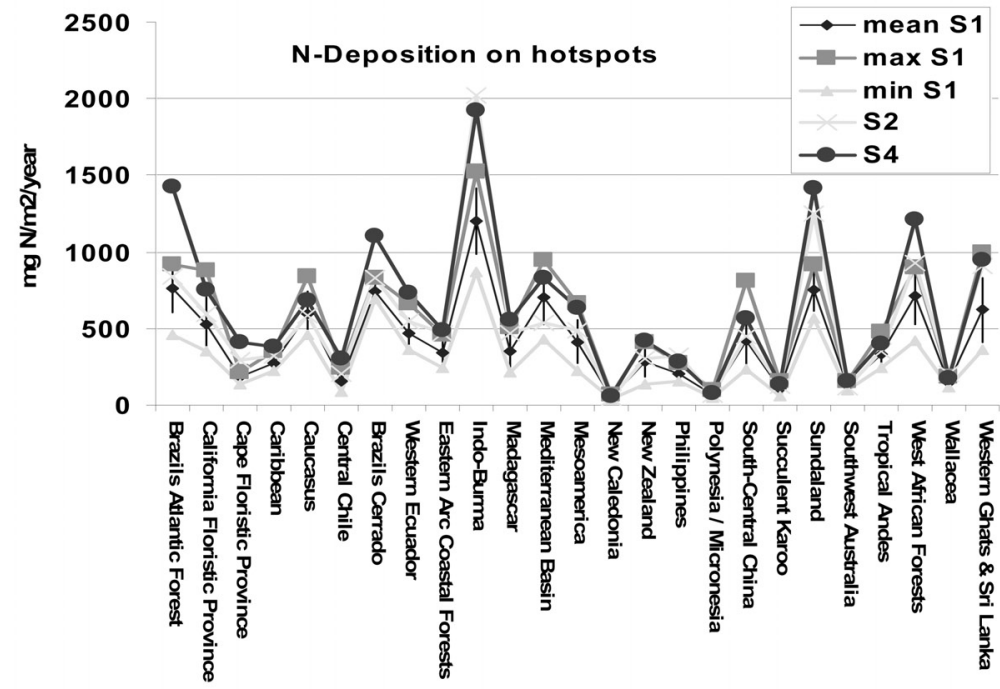

B

Figure 12. (a) Fraction (\%) of natural vegetation with $\mathrm{Nr}$ deposition larger than $1 \mathrm{~g}(\mathrm{~N}) \mathrm{m}^{-2} \mathrm{yr}^{-1}$ (or $\left.10 \mathrm{~kg}(\mathrm{~N}) \mathrm{ha}^{-1} \mathrm{yr}^{-1}\right)$. S3 includes $\mathrm{NH}_{\mathrm{x}}$ deposition results from $\mathrm{S} 2$. (b) Nitrogen deposition $\mathrm{mg}(\mathrm{N}) \mathrm{m}^{-2} \mathrm{yr}^{-1}$ on ecological hotspot areas [Phoenix et al., 2006].

beyond the scope of this study. However, we think there are possible ways to stabilize or even reduce global $\mathrm{NH}_{3}$ emissions. For instance, owing to serious eutrophication problems, some countries such as the Netherlands have introduced measures that reduced $\mathrm{NH}_{3}$ emissions by almost a factor of two during the last 15 years, while maintaining a high level of food production. It can be expected that, for example, China, which is faced with enormous eutrophication problems, will in future optimize fertilizer use.

[39] We used worldwide wet deposition measurements to evaluate our calculations for the year 2000. For this purpose, we gathered results from deposition networks in North America, Europe, Africa and Southeast Asia, and added measurements for South America, India and remote stations. Wet deposition of nitrate (taken as the sum of $\mathrm{HNO}_{3}$ and aerosol nitrate) is in relatively good accordance with measurements in most continents, with $60-70 \%$ of the model calculated deposition agreeing within $\pm 50 \%$ with measurements. These results are in good agreement with the previous study by Lamarque et al. [2005] on $\mathrm{NO}_{\mathrm{y}}$ deposition in 2000 using an ensemble of nine models. Despite good agreement of the average model results, in South America the low spatial correlation indicates problems in either the models or emissions or the measurements. In India, modeled nitrate deposition is strongly underestimated by $130 \mathrm{mg}(\mathrm{N}) \mathrm{m}^{-2} \mathrm{yr}^{-1}$, roughly a factor of 2 . 
[40] The agreement of $\mathrm{NH}_{\mathrm{x}}$ deposition with measurements is generally somewhat less than for $\mathrm{NO}_{\mathrm{y}}$, with $30-60 \%$ of the modeled deposition within $50 \%$ of the measurements. The mean model bias is small in most regions, except for East Asia where measurements indicate 50\% higher $\mathrm{NH}_{\mathrm{x}}$ deposition, and India where the model overestimates $\mathrm{NH}_{\mathrm{x}}$ measurements with $200-300 \mathrm{mg}(\mathrm{N}) \mathrm{m}^{-2} \mathrm{yr}^{-1}$ or almost a factor of 2 . Our study cannot identify whether measurement problems, model errors such as the neglect of mineral dust, or perhaps most importantly inaccurate emission inventories are causing these discrepancies. A comparison with $\mathrm{NH}_{3}$ measurements from passive samplers and comparison of aerosol concentrations may shed some light on this discrepancy. In general a good agreement of $\mathrm{SO}_{4}$ deposition is found with $60-80 \%$ of the model results agreeing to within $50 \%$ of the measurements. Only in East Asia, $\mathrm{SO}_{4}$ deposition is strongly underestimated. We propose two possible reasons for this discrepancy: The $\mathrm{SO}_{2}$ emission factor of coal used in our study could be too low, but we also suspect that the measured $\mathrm{SO}_{4}$ deposition is substantially influenced by $\mathrm{SO}_{4}$ related to mineral dust, where in the models the calculated $\mathrm{SO}_{4}$ strictly refers to products of anthropogenic and biogenic emissions. The mean of model results showed a good performance compared to measurements, effectively canceling out outliers from individual model results.

[41] In our study we solely used wet deposition measurement to evaluate deposition. This means that we did not evaluate other modeled and measured parameters that could give additional information on deposition fluxes, i.e., concentrations of aerosol and precursor gases, rainfall rates and micrometeorological parameters needed to calculate dry deposition fluxes. However, the AEROCOM model intercomparison exercise (http://nansen.ipsl.jussieu.fr/ AEROCOM/) evaluated in parallel to this work the aerosol calculations by a host of global models. Some of the models that participated in this study also contributed results to AEROCOM. Taking all aerosol types together, models underestimate aerosol optical depth by 30-40\% [Kinne et al., 2005]. Large regional differences in aerosol removal processes and residence times were identified [Textor et al., 2005]. This is confirmed by our analysis of the relative importance of wet deposition, which typically varied between 40 and $70 \%$ of the total deposition among models. Differences in rainfall, but perhaps more importantly in the parameterizations of the wet removal by that rain, may cause these discrepancies, but were not further analyzed in this study. Also, large variations in dry deposition parameterization and the resulting deposition velocities will add to the uncertainties. We showed that model resolution may contribute to model variations, but is perhaps not the most important one, since at a distance of a few hundred kilometers from the high-emission regions deposition patterns are rather similar. These model differences are translated into a variability of total deposition of about $30 \%$ in the emission regions, despite the use of prescribed emissions. We showed that in ecological hotspot regions, the variations may be around $50 \%$, and in remote regions, such as the Northern Polar Regions and $\mathrm{SH}$ the relative variability is up to a factor of 2 . Our study indicates that substantial fractions of the mainly land-borne emissions are deposited into the coastal and open oceans: $43 \%$ and $7 \%$ of all $\mathrm{NO}_{\mathrm{y}}$ deposition is on the open ocean and coastal zones, respectively. Less $\mathrm{NH}_{\mathrm{x}}$ is deposited on the coastal and open sea: $6 \%$ and 36\%; whereas for $\mathrm{SO}_{\mathrm{x}}$ the large contribution of volcanic and DMS emission lead to a larger deposition on ocean (51\%) and coastal systems (8\%).

[42] Consistent with the CLE emission scenario, $\mathrm{NO}_{\mathrm{y}}$ deposition remains roughly unchanged in 2030 in most parts of the world, with the exception of Asia where $\mathrm{NO}_{\mathrm{y}}$ deposition further increases by $50 \%$ to $100 \%$. $\mathrm{NO}_{\mathrm{y}}$ deposition for MFR could decrease by 50\% worldwide upon introduction of advanced NO emission control techniques; however, deposition in Africa and Oceania are changing less owing to dominance of natural $\mathrm{NO}_{\mathrm{x}}$ emissions. A2 would imply further increases of $\mathrm{NO}_{\mathrm{y}}$ deposition in the polluted parts of the world by a factor of 2 .

[43] $\mathrm{NH}_{4}$ deposition decreases by $20 \%$ in Europe assuming CLE, but increases by $40-100 \%$ in Central and South America, Africa, and parts of Asia. The results from the A2 scenario are rather similar to the CLE assumptions, but differ in Europe, where no emission reductions are realized under A2. Deposition of $\mathrm{SO}_{\mathrm{x}}$ varies strongly among the scenarios. For CLE, sulfur deposition remains constant or goes down everywhere, except in Asia. Assuming MFR, large reductions in deposition can be realized throughout the world, whereas A2 implies large increases in deposition everywhere except for North America and Europe.

[44] Climate change in 2030 is predicted to have fairly small impacts on deposition, compared to the emission induced changes; the changes seem to be mainly related to changes in monsoon circulation and associated precipitation. Changes in the atmospheric composition (e.g., oxidants) and hence the chemical lifetime and transport distance influence deposition patterns of the aerosol and aerosol precursor. Our experiments cannot assess the significance of these processes, since we varied all processes at the same time. Dedicated tracer experiments would be required to isolate the feedback mechanisms per component and region. However, from analysis of regional wet to total deposition ratios for selected continents we can estimate that chemical feedback processes are not likely to change regional scale deposition by more than a few percent.

[45] Over land relatively large fractions of $\mathrm{NO}_{\mathrm{y}}, \mathrm{NH}_{\mathrm{x}}$ and $\mathrm{SO}_{\mathrm{x}}$ are deposited on natural vegetation, typically between 50 and $80 \%$, indicating the importance of atmospheric transport in dispersing pollution from agricultural and industrial emission regions to the surrounding natural ecosystems. A first analysis of the regions exposed to nitrogen deposition in excess of $10 \mathrm{~kg}(\mathrm{~N}) \mathrm{ha}^{-1} \mathrm{yr}^{-1}$ (or $\left.1 \mathrm{~g}(\mathrm{~N}) \mathrm{m}^{-2} \mathrm{yr}^{-1}\right)$, which is the lower threshold value for sensitive ecosystems, shows that substantial parts of the world ecosystems, especially in Europe, parts of Africa and Asia, can be potentially damaged by excessive inputs of $\mathrm{Nr}$. Except for Europe, the current legislation regarding air pollutant emissions does not substantially improve this situation, whereas substantial improvements could be made considering MFR for $\mathrm{NO}_{\mathrm{y}}$. It would be interesting to evaluate how $\mathrm{NH}_{3}$ emission abatement could reduce $\mathrm{Nr}$ deposition to below the threshold. We note here that in 
order to make a careful analysis of potential to eutrophication risk for ecosystems a more detailed analysis per ecosystem and soil type is needed. We plan to do this analysis in a follow-up project along with an analysis of soil sensitivity to acidification. Further, we recommend refining our study with higher-resolution regional-scale models.

[46] A further important link of nitrogen deposition and ecosystems is the response of $\mathrm{N}_{2} \mathrm{O}$ emissions in coastal and terrestrial ecosystems, and the possible increased carbon uptake in terrestrial ecosystems. Deposition fields in this study will be made available for further assessments.

[47] This work was part of a larger analysis of a multimodel assessment of the impacts of various emission scenarios on atmospheric composition. Other aspects of this study focused on changes in lifetimes and budgets of ozone, $\mathrm{CO}, \mathrm{NO}_{2}$ columns and $\mathrm{OH}$ radical, radiative forcing, air quality and surface ozone. Some information arising from those studies is consistent with our findings here. For example, the modeled underestimate of $\mathrm{NO}_{\mathrm{y}}$ deposition in China is also found in the comparison of modeled and measured $\mathrm{NO}_{2}$ from the GOME satellite. However, also in Europe and North America, GOME $\mathrm{NO}_{2}$ seems higher than calculated by our models, which is not confirmed by our modeled deposition. In India, retrieved $\mathrm{NO}_{2}$ and measured $\mathrm{NO}_{\text {y }}$ deposition seem, despite large uncertainties, relatively consistent with the model calculations. However, most models seem to strongly overestimate the surface ozone resulting from the NO emissions.

[48] This study showed that it is important to enforce current worldwide air quality legislation (CLE) when considering current exposure of ecosystems to eutrophying and acidifying deposition. Introduction of all currently known technical measures would be expected to substantially decrease the ecosystem exposure to $\mathrm{N}$ deposition. Especially in Asia, further studies on the impact of $\mathrm{NH}_{\mathrm{x}}$ deposition on ecosystems would be necessary. Nonattainment of these policy objectives, such as expressed in SRES-A2, would lead to adverse impacts on ecosystems along with a negative impact on air quality [Dentener et al., 2005, 2006; Shindell et al., 2006; West and Fiore, 2005] and radiative forcing of climate [Stevenson et al., 2006].

[49] Acknowledgments. We thank the scientists involved in the continuous collection and analysis of precipitation samples, work essential for this study. We thank Sergey A. Gromov for assistance with the use of EAnet data and Thorjorn Larsen for providing measurements from the IMPACTS study. This model exercise was organized under the umbrella of the EC FP6 Network of Excellence ACCENT. Participation of the Lawrence Livermore National Laboratory authors occurred through the University of California under the auspices of the U.S. Department of Energy contract W-7405-ENG-48.

\section{References}

Aardenne, J. A., F. J. Dentener, J. G. J. Olivier, C. G. M. Klein Goldewijk, and J. Lelieveld (2001), A $1^{\circ} \times 1^{\circ}$ resolution data set of historical anthropogenic trace gas emissions for the period 1890-1990, Global Biogeochem. Cycles, 15, 909-928.

Andreae, M. O., and P. Merlet (2001), Emission of trace gases and aerosols from biomass burning, Global Biogeochem. Cycles, 15, 955-966.

Bobbink, R., M. Hornung, and J. M. Roelofs (1998), The effects of airborne pollutants on species diversity in natural and semi-natural European vegetation, J. Ecol., 86, 717-738.

Bouwman, A. F., D. S. Lee, W. A. H. Asman, F. J. Dentener, K. W. van der Hoek, and J. G. J. Olivier (1997), A global high-resolution emission inventory for ammonia, Global Biogeochem. Cycles, 11, 561-587.
Bouwman, A. F., L. J. M. Boumans, and N. H. Batjes (2002a), Estimation of global $\mathrm{NH}_{3}$ volatilization loss from synthetic fertilizers and animal manure applied to arable lands and grasslands, Global Biogeochem. Cycles, 16(2), 1024, doi:10.1029/2000GB001389.

Bouwman, A. F., D. P. Van Vuuren, R. G. Derwent, and M. Posch (2002b), A global analysis of acidification and eutrophication of terrestrial ecosystems, Water Air Soil Pollut., 141, 349-382, doi:10.1023/A:1021398008726.

Crutzen, P. J. (1974), Photochemical reactions initiated by and influencing ozone in unpolluted tropospheric air, Tellus, 26, 46-57.

Dentener, F. J., and P. J. Crutzen (1994), A three-dimensional model of the global ammonia cycle, J. Atmos. Chem., 19, 331-369.

Dentener, F., D. Stevenson, J. Cofala, R. Mechler, M. Amann, P. Bergamaschi, F. Raes, and R. Derwent (2005), The impact of air pollutant and methane emission controls on tropospheric ozone and radiative forcing: CTM calculations for the period 1990-2030, Atmos. Chem. Phys., 5, $1731-1755$.

Dentener, F., et al. (2006), Global Atmospheric Environment for the next generation, Environ. Sci. Technol., 40, 3586-3594.

EANET (2001), Data report on the acid deposition in the East Asian region 2000, Network Cent. for EANET, Niigata, Japan.

Eickhout, B., M. G. J. Den Elzen, and G. J. J. Kreileman (2004), The Atmosphere-Ocean System of IMAGE 2.2: A global model approach for atmospheric concentrations, and climate and sea level projections, report, Natl. Inst. for Public Health and the Environ., Bilthoven, Netherlands

Emberson, L. D., M. R. Ashmore, H. M. Cambridge, D. Simpson, and J. P. Tuovinen (2000), Modelling stomatal ozone flux across Europe, Environ. Pollut., 109(3), 403-413.

Eyring, V., H. W. Koehler, A. Lauer, and H. Lemper (2005), Emissions from international shipping: 2. Impact of future technologies on scenarios until 2050, J. Geophys. Res., 110, D17306, doi:10.1029/2004JD005620.

Filoso, S., M. R. Williams, and J. M. Melack (1999), Composition and deposition of throughfall in a flooded forest archipelago, Biogeochemistry, 45(2), doi:10.1023/A:1006108618196.

Finlayson-Pitts, B. J., and J. N. Pitts (1986), Atmospheric Chemistry: Fundamentals and Experimental Techniques, 1098 pp., John Wiley, Hoboken, N. J.

Galloway, J. N., et al. (2004), Nitrogen cycles: Past, present and future, Biogeochemistry, 70, 153-226.

Galy-Lacaux, C., H. Al Ourabi, J. N. Galloway, J. P. Lacaux, J. Mphepya, K. Pienaar, V. Pont, L. Sigha, and V. Yoboué (2003), Dry and wet atmospheric nitrogen deposition in Africa, IGAC Newsl., 27, 6-11.

Grassian, V. H. (2001), Heterogeneous uptake and reaction of nitrogen oxides and volatile organic compounds on the surface of atmospheric particles including oxides, carbonates, soot and mineral dust: Implications for the chemical balance of the troposphere, Int. Rev. Phys. Chem., $20(3), 467-548$.

Isaksen, I., et al. (1999), Modeling the chemical composition of the future atmosphere, in IPCC, Aviation and the Global Atmosphere, edited by J. Penner et al., pp. 121-164, Cambridge Univ. Press, New York.

Jaeglé, L., R. V. Martin, K. Chance, L. Steinberger, T. P. Kurosu, D. Jacob, A. I. Modi, V. Yoboué, L. Sigha, and C. Galy-Lacaux (2004), Satellite mapping of rain induced nitrite oxide emission form soils, J. Geophys. Res., 109, D21310, doi:10.1029/2004JD004787.

Kinne, S., et al. (2005), An AeroCom initial assessment-Optical properties in aerosol component modules of global models, Atmos. Chem. Phys., 6, $1815-1834$.

Kuhlshrestha, U., L. Granat, M. Enghardt, and H. Rodhe (2005), Review of precipitation chemistry studies in India-A search for regional patterns, Atmos. Environ., 39, 7403-7419.

Lamarque, J. F., et al. (2005), Assessing future nitrogen deposition and carbon cycle feedback using a multi-model approach: Analysis of nitrogen deposition, J. Geophys. Res., 110, D19303, doi:10.1029/ 2005JD005825.

Lara, L. B. L. S., P. Artaxo, L. A. Martinelli, R. L. Victoria, P. B. Camargo, A. Krusche, G. P. Ayers, E. S. B. Ferraz, and M. V. Ballester (2001), Chemical composition of rainwater and anthropogenic influences in the Piracicaba river basin, southeast Brazil, Atmos. Environ., 35, $4937-4945$

Larsen, T., T. Dagan, and H. Yi (2004), Integrated monitoring programme on acidification of Chinese Terrestrial Systems: IMPACTS, report, 99 pp., Norw. Inst. for Water Res. (NIVA), Oslo.

Lelieveld, J., W. Peters, M. C. Krol, and F. J. Dentener (2002), The global stability of hydroxyl chemistry, J. Geophys. Res., 107(D23), 4715 , doi:10.1029/2002JD002272.

Mauzerall, D. M., and X. Wang (2001), Protecting agricultural crops from the effects of tropospheric ozone exposure: Reconciling science and standard setting in the United States, Europe, and Asia, Annu. Rev. Energy Environ., 26, 237-268, doi:10.1146/annurev.energy.26.1.237. 
Metzger, S., F. Dentener, J. Lelieveld, A. Jeuken, M. Krol, and S. Pandis (2002), Gas/Aerosol Partitioning II: Global modeling results, J. Geophys. Res., 107(D16), 4313, doi:10.1029/2001JD001103.

Myers, N., R. A. Mittermeier, C. G. Mittermeier, G. A. B. da Fonseca, and J. Kent (2000), Biodiversity hotspots for conservation priorities, Nature, 403, 853-858.

Nakicenovic, N., et al. (2000), Special Report on Emissions Scenarios: Intergovernmental Panel on Climate Change, 599 pp., Cambridge Univ Press, New York.

Phoenix, G. K., et al. (2006), Atmospheric nitrogen deposition in world biodiversity hotspots: The need for a greater global perspective in assessing N deposition impacts, Global Change Biol., 12, 470-476, doi:10.1111/j.1365-2486.2006.01104.x.

Prentice, I. C., G. D. Farquhar, M. J. R. Fasham, M. L. Goulden, M. Heimann, V. J. Jaramillo, H. S. Kheshgi, C. Le Quéré, R. J. Scholes, and D. W. R. Wallace (2001), The carbon cycle and atmospheric carbon dioxide, in Climate Change 2001: The Scientific Basis, edited by J. T. Houghton et al., pp. 183-237, Cambridge Univ. Press, New York.

Rabalais, N. N. (2002), Nitrogen in aquatic ecosystems, Ambio, 31(2), $102-112$.

Rodhe, H., F. Dentener, and M. Schulz (2002), The global distribution of acidifying wet deposition, Environ. Sci. Technol., 36(20), 4382-4388.

Sala, O. E., et al. (2000), Global biodiversity scenarios for the year 2100 , Science, 87, 1770-1774.

Seitzinger, S. P., and C. Kroeze (1998), Global distribution of nitrous oxide production and $\mathrm{N}$ inputs in freshwater and coastal marine ecosystems, Global Biogeochem. Cycles, 12(1), 93-113.

Shindell, D., et al. (2006), Multi-model simulations of carbon monoxide: Comparison with observations and projected near-future changes, J. Geophys. Res., doi:10.1029/2006JD007100, in press.

Stevenson, D. S., et al. (2006), Multimodel ensemble simulations of present-day and near-future tropospheric ozone, J. Geophys. Res., 111, D08301, doi:10.1029/2005JD006338.

Streets, D. G., et al. (2003), An inventory of gaseous and primary aerosol emissions in Asia in the year 2000, J. Geophys. Res., 108(D21), 8809, doi:10.1029/2002JD003093.

Taylor, K. E. (2001), Summarizing multiple aspects of model performance in a single diagram, J. Geophys. Res., 106(D7), 7183-7192.

Textor, C., et al. (2005), Analysis and quantification of the diversities of aerosol life cycles within AeroCom, Atmos. Chem. Phys., 6, 17771813.

Van der Werf, G. R., T. J. Randerson, J. Collatz, and L. Giglio (2003) Carbon emissions from fires in tropical and subtropical ecosystems, Global Change Biol., 9, 547-562.

van Noije, T. P. C., et al. (2006), Multi-model ensemble simulations of tropospheric $\mathrm{NO}_{2}$ compared with GOME retrievals for the year 2000 , Atmos. Chem. Phys., 6, 2943-2979.

Vitousek, P. M., J. D. Aber, R. W. Howarth, G. E. Likens, P. A. Matson, D. W. Schindler, W. H. Schlesinger, and D. G. Tillman (1997), Human alteration of the global nitrogen cycle: Sources and consequences, Ecol. Appl., 7(3), 737-750.

Wang, Y., and D. J. Jacob (1998), Anthropogenic forcing on the tropospheric ozone and $\mathrm{OH}$ since preindustrial times, J. Geophys. Res., 103(D23), 31,123-31,135.

West, J. J., and A. M. Fiore (2005), Management of tropospheric ozone by reducing methane emissions, Environ. Sci. Technol., 39(13), 4685-4691, doi:10.1021/es048629f.

Whelpdale, D. M., P. W. Summers, and E. Sanhueza (1997), A global overview of atmospheric acid deposition fluxes, Environ. Monit. Assess. $48,217-247$

World Health Organization (2003), Health aspects of air pollution with particulate matter, ozone and nitrogen dioxide, report, 98 pp., Bonn, Germany.

C. Atherton and D. Bergman, Atmospheric Science Division, Lawrence Livermore National Laboratory, 7000 East Avenue, Livermore, CA 94550 , USA. (atherton2@1ln1.gov; dbergmann@1lnl.gov)
N. Bell and D. Shindell, NASA-Goddard Institute for Space Studies, 2880 Broadway New York, NY 10025, USA. (nbell@giss.nasa.gov; dshindell@giss.nasa.gov)

I. Bey and J. Drevet, Swiss Federal Institute of Technology (EPFL), EPFLENAC-ISTE-LMCA, Station 2, Lausanne CH-1015, Switzerland. (isabelle. bey@epfl.ch; jerome.drevet@epfl.ch)

T. Butler and M. Lawrence, Max Planck Institute for Chemistry, Postfach 3060, D-55020 Mainz, Germany. (tmb@mpch-mainz.mpg.de; lawrence@ mpch-mainz.mpg.de)

J. Cofala, International Institute for Applied Systems Analysis, A-2361 Laxenburg, Austria. (cofala@iiasa.ac.at)

B. Collins and M. Sanderson, Met Office, Fitzroy Road, Exeter EX1 3PB, UK. (bill.collins@metoffice.com; michael.sanderson@metoffice.com)

F. Dentener, European Commission, Institute for Environment and Sustainability, Joint Research Centre, TP290, I-21020 Ispra, Italy. (frank.dentener@jrc.it)

R. Doherty and D. Stevenson, School of Geosciences, Institute for Atmospheric and Environmental Science, Crew Building, University of Edinburgh, King's Buildings, Edinburgh EH9 3JN, UK. (ruth.doherty@ ed.ac.uk; davids@met.ed.ac.uk)

B. Eickhout, Netherlands Environmental Assessment Agency, Postbus 303, NL-3720 AH, Bilthoven, Netherlands. (bas.eickhout@mnp.nl)

K. Ellingsen and M. Gauss, Department of Geosciences, University of Oslo, PO 1022 Blindern, N-0315 Oslo, Norway. (kjerstin.ellingsen@geo. uio.no; michael.gauss@geo.uio.no)

A. M. Fiore and L. W. Horowitz, Geophysical Fluid Dynamics Laboratory, NOAA, 201 Forrestal Road, Princeton, NJ 08542-0308, USA. (arlene.fiore@noaa.gov; larry.horowitz@noaa.gov)

J. Galloway, Department of Environmental Sciences, University of Virginia, P.O. Box 400123, Charlottesville, VA 22904-4123, USA. (jng@ virginia.edu)

C. Galy-Lacaux and F. Solmon, Laboratoire d'Aérologie, Observatoire Midi-Pyrénées, 14 Avenue Edouard Belin, F-31400 Toulouse, France. (lacc@aero.obs-mip.fr; solf@aero.obs-mip.fr)

D. Hauglustaine and S. Szopa, Laboratoire des Sciences du Climat et de l'Environnement (LSCE), CEN Saclay, Orme des Merisiers, Bat. 712, F-91191 Gif-sur-Yvette, France. (didier@1sce.saclay.cea.fr; sophie.szopa@ cea.fr)

M. Krol, IMAU/SRON/Wageningen University, Princetonplein 5, NL3584 CC Utrecht, Netherlands. (krol@phys.uu.nl)

U. C. Kulshrestha, Analytical and Environmental Chemistry Division, Indian Institute of Chemical Technology, Hyderabad 500 007, India (umesh_iict@rediffmail.com)

J. F. Lamarque, Atmospheric Chemistry Division, NCAR, P.O. Box 3000, Boulder, CO 80307, USA. (lamar@ucar.edu)

V. Montanaro and G. Pitari, Dipartimento di Fisica, Università L'Aquila, Via Vetoio Località Coppito, I-67100 l'Aquila, Italy. (veronica. montanaro@aquila.infn.it; pitari@aquila.infn.it)

J. F. Müller, Belgium Institute for Space Aeronomy, Ringlaan 3, B-1180, Brussels Belgium. (jean-francois.muller@bira-iasb.oma.be)

S. Rast, Max Planck Institute for Meteorology, Bundesstrasse 53 , D-20146 Hamburg, Germany. (rast@dkrz.de)

J. Rodriguez and S. Strahan, Goddard Earth Science and Technology Center (GEST), 5523 Research Park Drive, Suite 320, Baltimore, MD 21228, USA. (jrodriguez@hyperion.gsfc.nasa.gov; strahan@prometheus. gsfc.nasa.gov)

M. Schultz, ICG-II, Research Center, D-52425 Jülich, Germany. (m.schultz@fz-juelich.de)

K. Sudo, Atmospheric Composition Research Program, Frontier Research Center for Global Change, 3173-25 Showa-machi, Kanazawa-ku, Yokohama 236-0001, Japan. (kengo@jamstec.go.jp)

T. Van Noije, Atmospheric Composition, Climate Research and Seismology Department, Royal Netherlands Meteorological Institute (KNMI), PO Box 201, NL-3730 AE De Bilt, Netherlands. (twan.van. noije@knmi.nl)

O. Wild, Centre for Atmospheric Science, Department of Chemistry, Lensfield Road, Cambridge CB2 1EW, UK. (oliver.wild@atm.ch.cam.ac.uk) 